\title{
Problems of the starting and operating of hydraulic components and systems in low ambient temperature
}

\author{
Part II \\ Determining the clearance between cooperating elements during \\ the hydraulic components start-up in extremely low ambient \\ temperatures on the grounds of experimental research
}

Ryszard Jasiński, Ph. D.

Gdansk University of Technology

\begin{abstract}
Severe winters and sweltering summers which more and more often occur nowadays are the reason why machinery designers face many difficulties when designing devices which will be serviceable in extreme ambient conditions. Hence, defining the principles and conditions of safe operation of hydraulically driven machines and devices is essential for their designers and operators. For this reasons the author did a series of tests of hydraulic component and systems in thermal shock conditions (cooled-down components were supplied with hot working medium). The experimental tests were carried out in the laboratory of the Chair of Hydraulics and Pneumatics, Gdańsk University of Technology. They gave answer to the question how the effective clearance changes in such conditions and what parameters it depends on. Based on temperature graphs acquired from tests of heating up elements of hydraulic components it is possible to determine precisely change of clearance between cooperating elements.
\end{abstract}

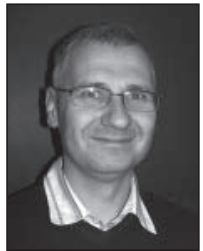

Keywords: hydraulic machines, hydraulic drives, diagnostics, hydraulic systems

\section{INTRODUCTION}

During the hydraulic components start-up in thermal shock conditions [1-9, 12-13] dynamic change of component's elements dimensions due to thermal expansion is often encountered. Changes in the element's clearings result in changes in the effective clearing between cooperating elements. Change of clearance is influenced, inter alia, by the temperature difference between hot oil and cold hydraulic unit, flow of working fluid, construction of the component, kind of material used and shape of component's elements.

Between the hydraulic component's cooperating elements small clearances appear, measuring from few up to dozens $\mu \mathrm{m}$. Experimental research of various hydraulic components operating in low ambient temperatures undertaken by the author, allows to answer the question how the effective clearance changes in such conditions and what parameters does it depend on. The research included three groups of hydraulic components' systems: supply system, control system and executive system. Fig. 1 presents the block diagram of typical hydraulic system exposed to sub-zero ambient temperatures. Main component of the supply system is the hydraulic pump, in the control system - valves and directional spool valve while in the executive system - hydraulic actuator (motor or cylinder).
Using own methodology [1-8], the Author has tested many components and entire hydraulic system in thermal shock conditions. Tested components were placed in the low temperatures chamber in which $-35^{\circ} \mathrm{C}$ temperature was reached. The components were supplied with the hot Total Azolla 46 mineral oil in the temperature ranging from $20^{\circ} \mathrm{C}$ to $55^{\circ} \mathrm{C}$. In the fixed and moving elements of components temperature sensors were placed, mainly thermocouples. The temperature, pressure and flow volume in the inlet and outlet channels of the components were also measured.

\section{HYDRAULIC PUMPS RESEARCH}

The object of the research were pumps of following various types: multi-piston axial pump of constant output with camshaft, multi-piston axial pump of variable output and two geared pumps.

Researched camshaft pump of PWK 27 type (Fig. 2) of unit capacity $27.5 \mathrm{~cm}^{3} / \mathrm{rev}$., operates at nominal pressure of $45 \mathrm{MPa}$, nominal speed of $1500 \mathrm{rpm}$ and maximum $3000 \mathrm{rpm}[19,23$, 24]. The pump is characterized by high pressure-mechanical efficiency reaching $98 \div 99 \%$, as well as by high overall efficiency at the level of $92 \div 94 \%$ [11].

Variable output multi-piston axial pump of PVM016R1D type (Fig. 3) is the smallest in the PVplus product line [21] and 


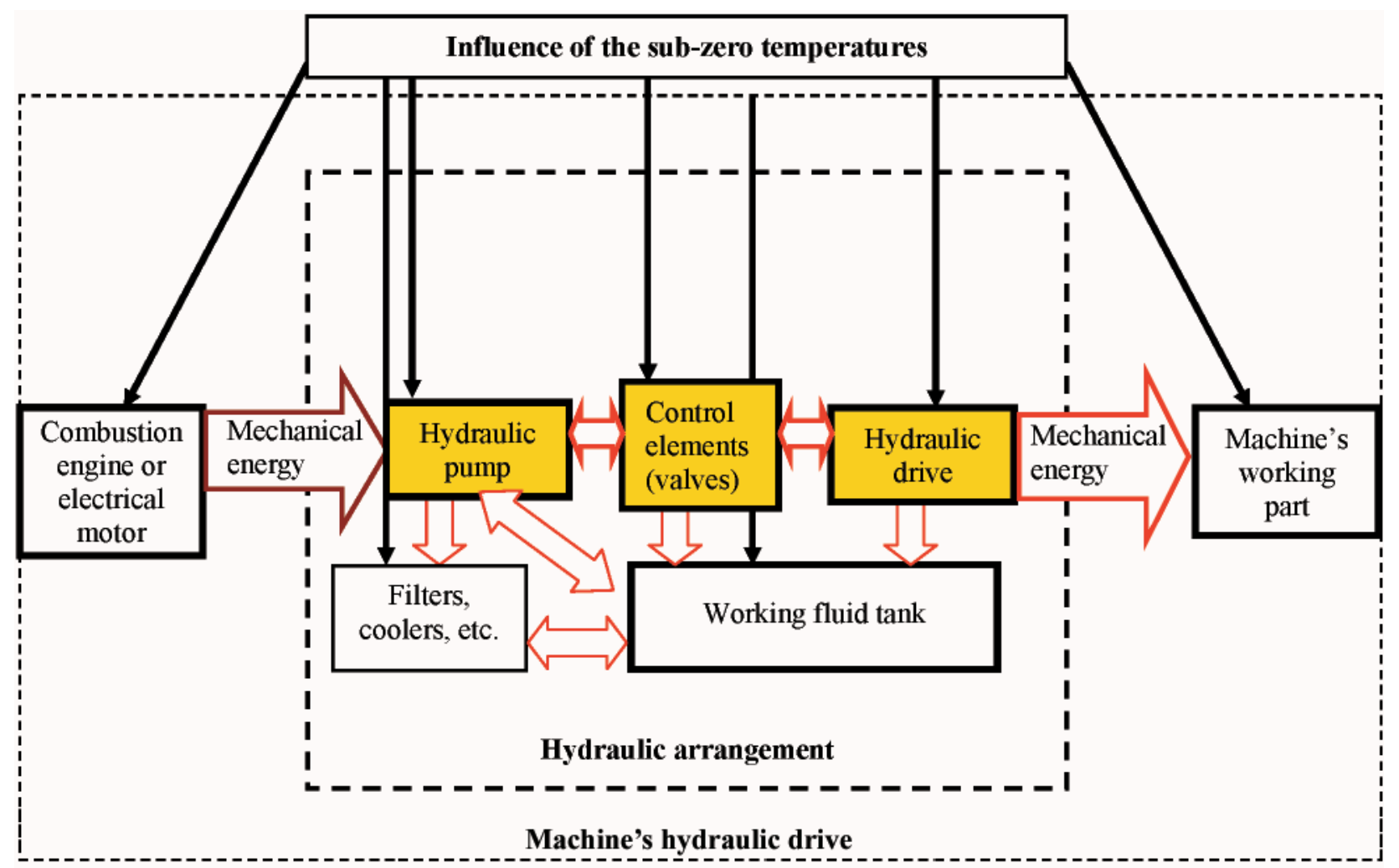

Fig. 1. Block diagram of machine's hydraulic drive with indication of the sub-zero temperatures influence on the operation of the component's systems

its characteristic parameters include: design output $16 \mathrm{~cm}^{3} / \mathrm{rev}$., nominal pressure $28 \mathrm{MPa}$, max. pressure $35 \mathrm{MPa}$ and rotation speed range between 300 and $3000 \mathrm{rpm}$.

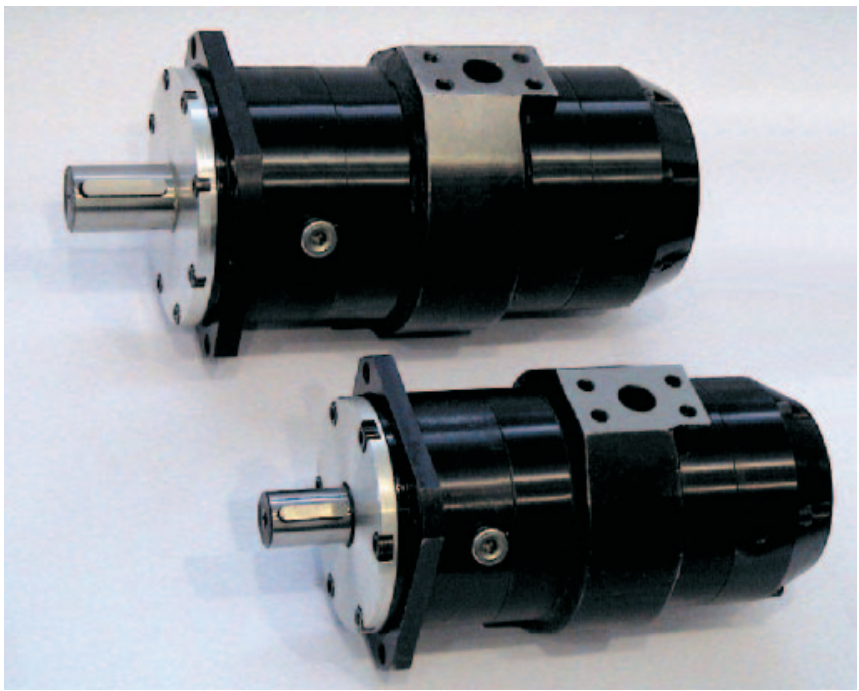

Fig. 2. Camshaft multi-piston pumps $P W K-27$ and $P W K-78$ from Hydrotor company [10, 11,19]

The arrangement consisting of PZ2-K-10 gear motor (Fig. 4) driving the PZ2-K-6.3 gear pump was tested.

Determining the changes of effective clearance between cooperating elements of multi-piston pump in thermal shock conditions.

In multi-piston radial and axial pumps or motors there are several places where loss of clearance between cooperating elements may occur. One of them is the effective clearance $(1)$ between pistons moving in the cylinder block holes (Fig. 5). Change of clearance may be determined during start-up $(\tau)$ according to formula:

$$
1_{e}(\tau)=1_{m}+\Delta l_{p}(\tau)-\Delta l_{t}(\tau)
$$

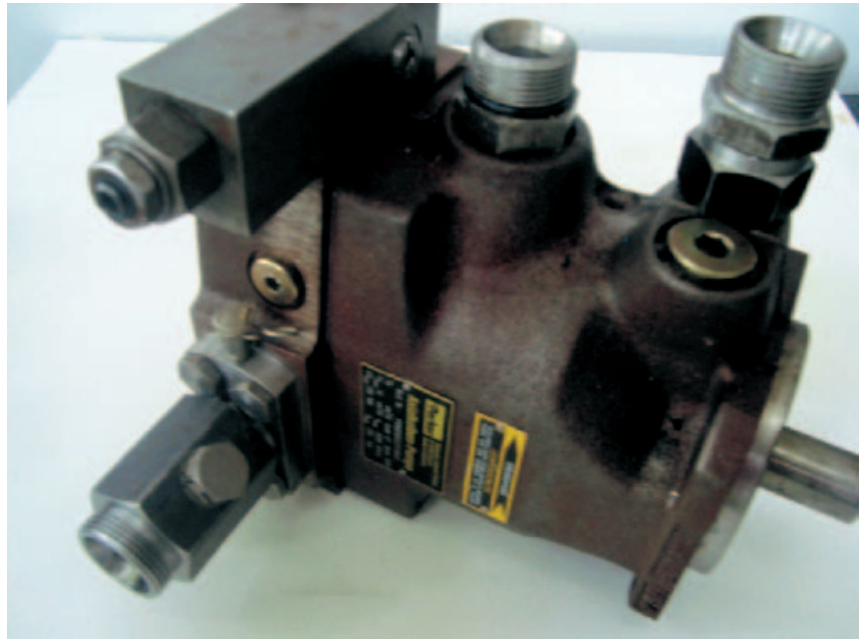

Fig. 3. Past-plate axial pump from Parker [21] company

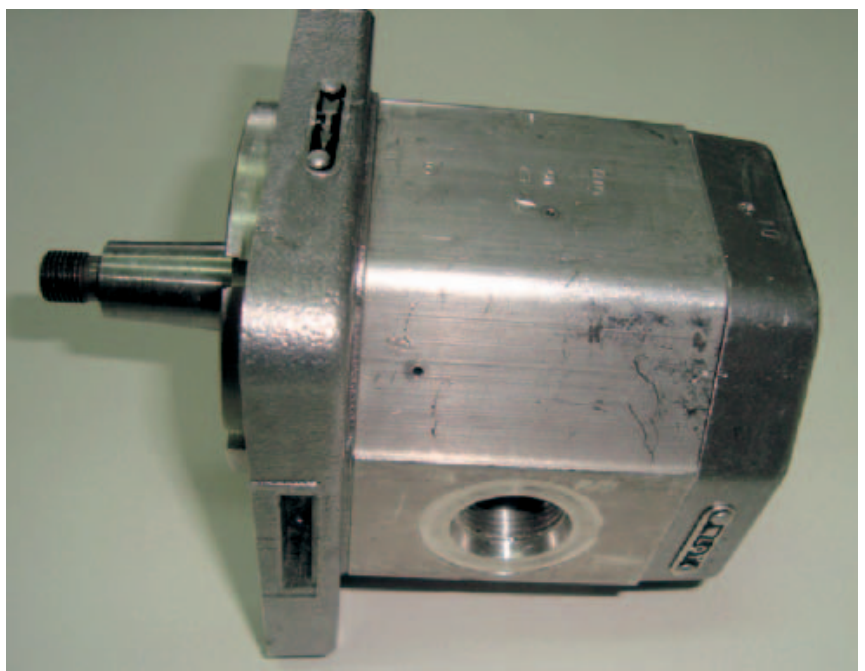

Fig. 4. Geared pump PZ2-K10 from Hydrotor company [19] 


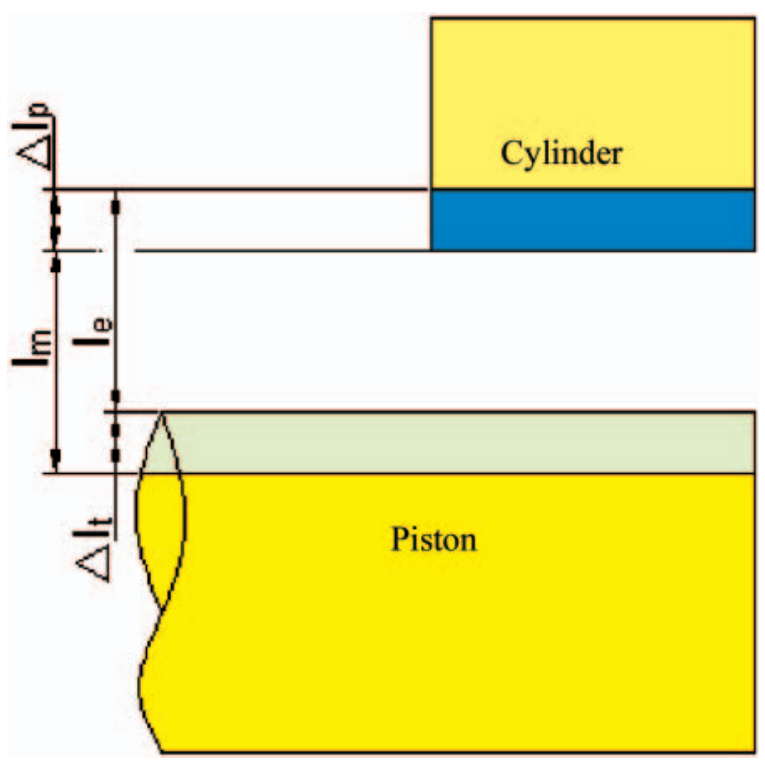

Fig. 5. Graphical interpretation of changes in the effective clearance

It describes the changes of clearance height: caused by pressure - related deformation of cylinder block and piston $\Delta \mathrm{l}_{\mathrm{p}}$ and by thermal expansion of both elements $\Delta \mathrm{l}_{\mathrm{t}}$.

Change of clearance height by the $\Delta \mathrm{l}_{t}$ value due to difference in linear thermal expansion of cooperating pump's (motor's) elements, in the effect of non-homogenous heating during start-up in thermal shock conditions may be described by the formula:

$$
\begin{gathered}
\Delta \mathrm{l}_{\mathrm{t}}(\tau)=\mathrm{h}_{\mathrm{T}} \cdot \beta_{\mathrm{T}} \cdot\left[\mathrm{T}_{\mathrm{T}}(\tau)-\mathrm{T}_{0}\right]+ \\
-\mathrm{h}_{\mathrm{B}} \cdot \beta_{\mathrm{B}} \cdot\left[\mathrm{T}_{\mathrm{B}}(\tau)-\mathrm{T}_{0}\right]
\end{gathered}
$$

where:

$\beta_{\mathrm{T}}, \beta_{\mathrm{B}}-$ linear thermal expansion coefficient's of piston (T) and cylinder block (B)

$\mathrm{T}_{\mathrm{T}}(\tau)$ - piston temperature

$\mathrm{T}_{\mathrm{B}}(\tau)$ - cylinder block temperature

$\mathrm{T}_{0}^{\mathrm{B}} \quad-$ measuring temperature of part's linear dimensions

$\mathrm{h}_{\mathrm{T}}, \mathrm{h}_{\mathrm{B}}$ - linear diameter dimension of: piston $(\mathrm{T})$ and distribution bush openings (B).

\section{PREPARING THE PWK27 PUMP FOR MEASURING THE CHANGE OF ELEMENTS' TEMPERATURE}

In the tested pump PWK (Fig. 2), built of two groups of elements: fixed (Fig. 6) and mobile (Fig. 7) the thermocouples were placed.

Mobile elements of the pump include: piston, screw throttle, hydrostatic slipper, distribution bush, resistance shield, clamping ring, separator, shaft, cam.

Fixed components of the pump include: cover, front housing, cylinder block, cylinder block cover, rear housing, guiding bush, socket.

Constant of temperature measurements allowed determination of the clearance between cooperating elements (pistons and cylinder bushes) of the pump during start-up in thermal shock conditions.

For the sake of researching the process of piston and slipper heating, they were purposely made with bores for fixing thermocouples. (Fig. 7, 8). Thermocouple leads placed in the slipper and piston were lead through purposefully made bores in the separator and cylinder block (Fig. 9).

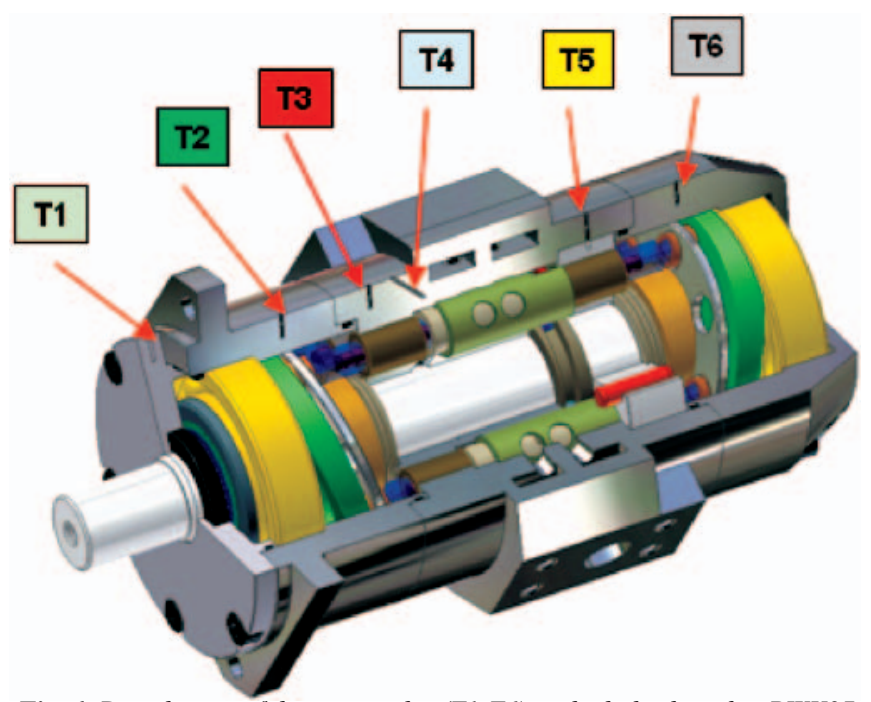

Fig. 6. Distribution of thermocouples (T1-T6) in the holes bored in PWK27 pump's fixed elements: $\boldsymbol{T} \mathbf{1}$ - cover, $\boldsymbol{T} \mathbf{2}$ - front housing, $\mathbf{T} \mathbf{3}$-cylinder block - area no. 1, T4-cylinder block-area no. 2, T5-cylinder block cover, T6 - rear housing
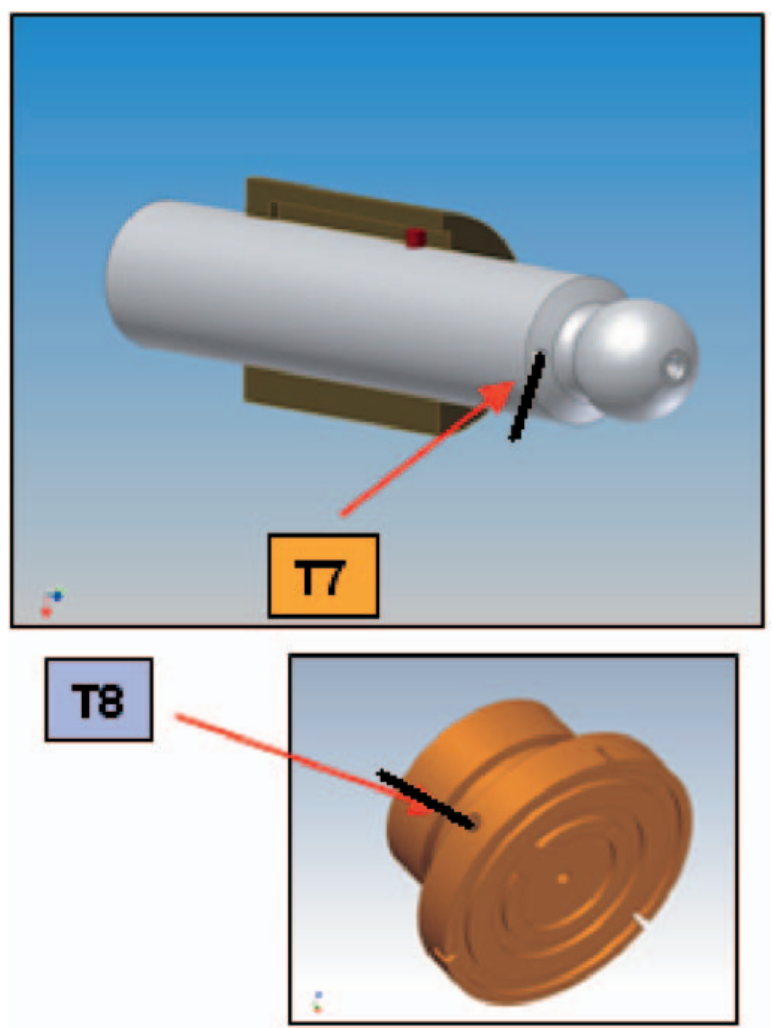

Fig. 7. Thermocouples in PWK27 pump's mobile parts: a) piston, b) hydrostatic foot

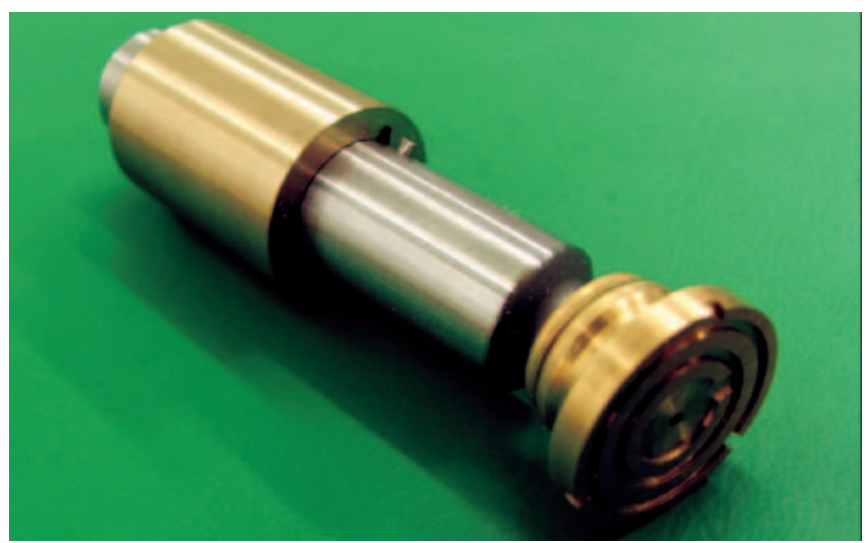

Fig. 8. Piston unit adapted to measuring the heating process 


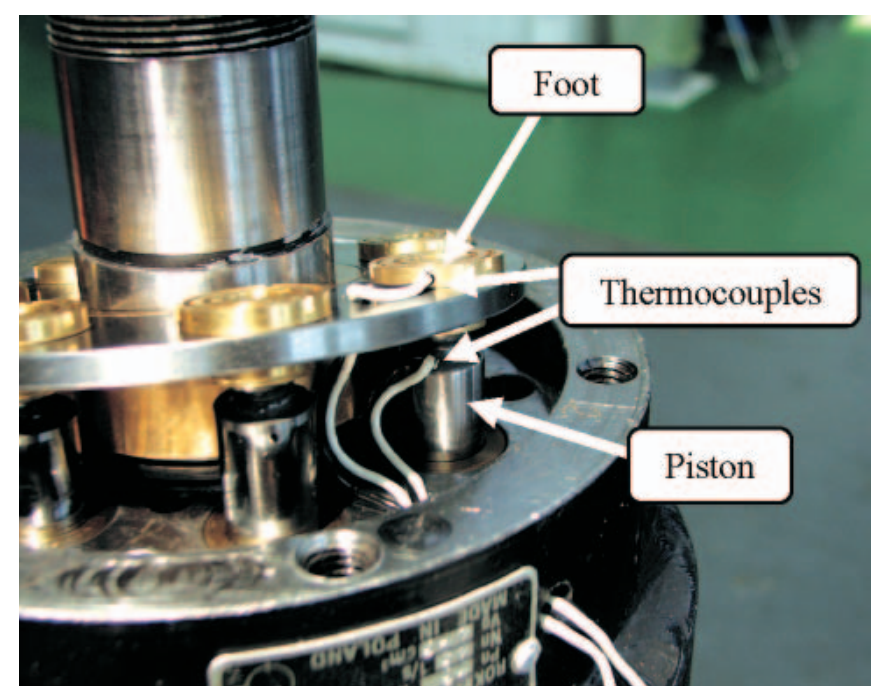

Fig. 9. Connection of thermocouples leads to the piston and hydrostatic foot in researched PWK27 pump

\section{RESEARCH OF PWK27 PUMP IN THERMAL SHOCK CONDITIONS}

Experimental research of PWK27 pump operation during start-up in thermal shock conditions were executed according to methodology [1] designated for the following start-up conditions:

$\star$ oil temperature: $\sim+48^{\circ} \mathrm{C}$

$\star$ ambient temperature: $-21 \div+23^{\circ} \mathrm{C}$

$\star$ pump's shaft rotation speed: $500 \div 2500 \mathrm{rpm}$

$\star$ pump's load: $4.5 \div 12 \mathrm{MPa}$.

Several measurement series of PWK27 pump start-up in thermal shock conditions were run. The results include, inter alia, characteristics of temperature change of: heating fixed elements, temperature of incoming and outgoing oil, temperature of leakages and characteristics of torque, oil pressure on the outlet, output, external leakage volume, rotation speed of the shaft, volumetric, torque and overall efficiency.

One start-up test of PWK27 pump was conducted for the following parameters: outlet pressure $9.15 \mathrm{MPa}$, output $30 \mathrm{dm}^{3} / \mathrm{min}$, pump's shaft rotation speed $1100 \mathrm{rpm}$, oil temperature $49^{\circ} \mathrm{C}$, ambient temperature $-12^{\circ} \mathrm{C}$.

On the grounds of recorded temperature graphs (Fig. 10) it is possible to determine that the fastest heating element in the pump is the cylinder block unit consisting of cylinder block and its cover.

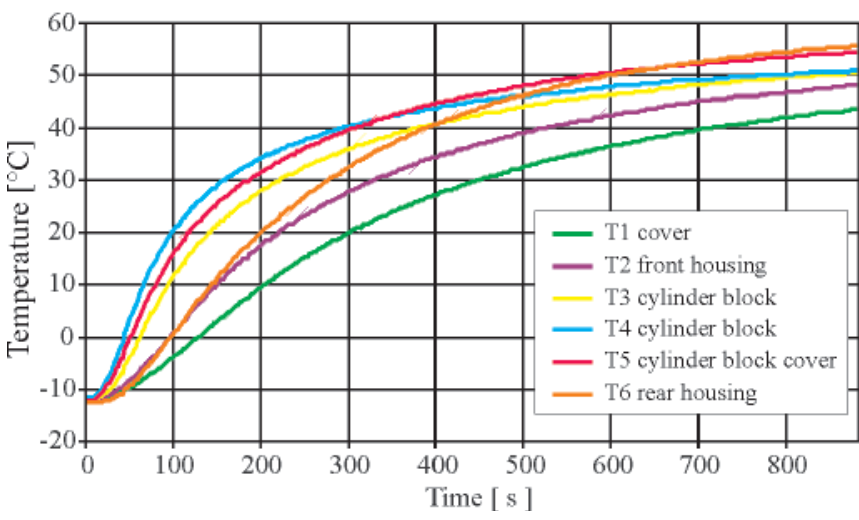

Fig. 10. Temperatures in pump's fixed parts (Fig. 6)
The fastest temperature build-up in the cylinder block occurs near the pump's internal canals that carry the main stream of hot oil and near the pump's camshaft (thermocouple measurement no. 4). Almost as quickly the temperature rises in the common areas of piston and guiding bush (thermocouple no. 5). Much slower however the temperature rises in front (thermocouple no. 2) and rear housing (thermocouple no. 6). In the first 200 seconds of pump's operation temperature graphs of the two are identical, only after that the rear housing begins to heat much quicker. It is this element that reaches the highest temperature of all the pump's fixed elements under set conditions of operation. Whereas the slowest heating up element is the pump's cover (thermocouple no. 1).

It is worth considering that same of PWK pump's fixed same elements (Fig. 10) while operating under constant pressure reach higher temperatures than this of the hot oil feeding the pump. This is exemplified by the comparison of characteristics on Fig. 11 with those on Fig. 10. It is the effect of friction heat generation in the stream of fluid flowing through pump's crankcase and mixed by the resistance shields of feet and pistons.

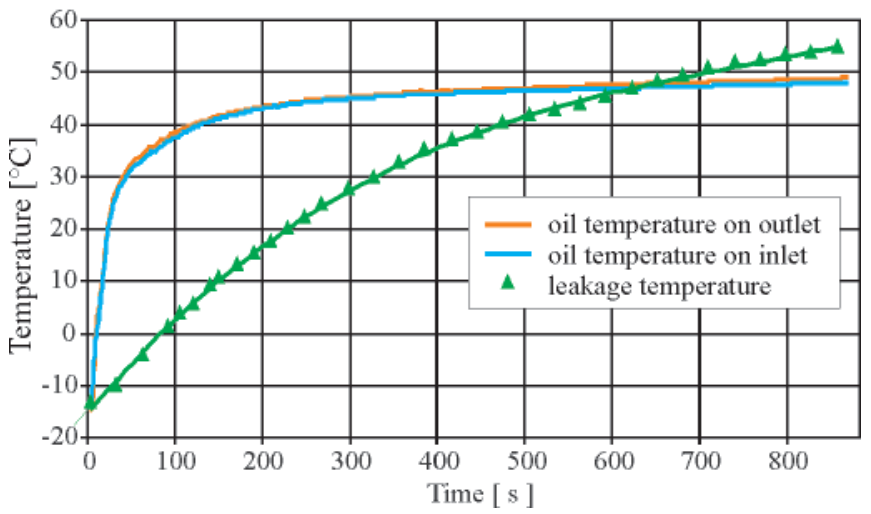

Fig. 11. Oil temperatures: on pump's inlet, on pump's outlet and external flows

In the initial period of pump's operation the temperature of leaking oil rises far slower than the temperature of main working stream on the inlet and outlet (Fig. 11). However, after some time the temperature of leakage reaches much higher temperature than the feeding stream temperature.

During tests PWK27 pump reached very high volumetric efficiency at least 0.98 (Fig. 12).

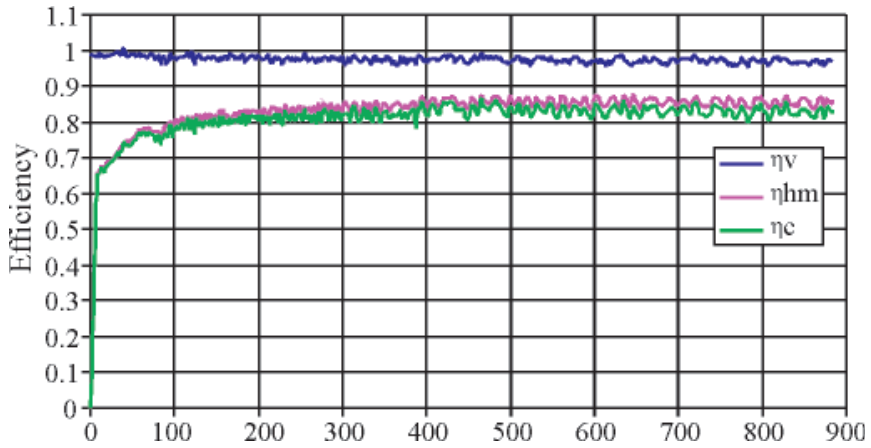

Fig. 12. Overall $\left(\eta_{1}\right)$, volumetric $\left(\eta_{1}\right)$ and torque $\left(\eta_{h m}\right)$ efficiency for the following parameters: working pressure $9.15 \mathrm{MPa}$, output $30 \mathrm{dm}^{3} / \mathrm{min}$, ambient temperature $-12^{\circ} \mathrm{C}$, oil temperature $49^{\circ} \mathrm{C}$

Torque efficiency remains at the level of 0.85 . It largely depends on pump's load that in the considered situation only amounted to $9 \mathrm{MPa}$. The higher is the working pressure of the pump, the higher its torque efficiency, and in the same time the lower its volumetric efficiency. 


\section{DETERMINING THE EFFECTIVE CLEARANCE BETWEEN THE PISTON AND CYLINDER OF THE PWK 27 PUMP}

On the grounds of analysis of several heating cycles of the piston achieved in few series of tests it was determined that the rate of piston heating is always lower or equal to the speed of the hydrostatic slipper heating. Fig. 13 presents the heating processes of the piston and the cylinder block cover.

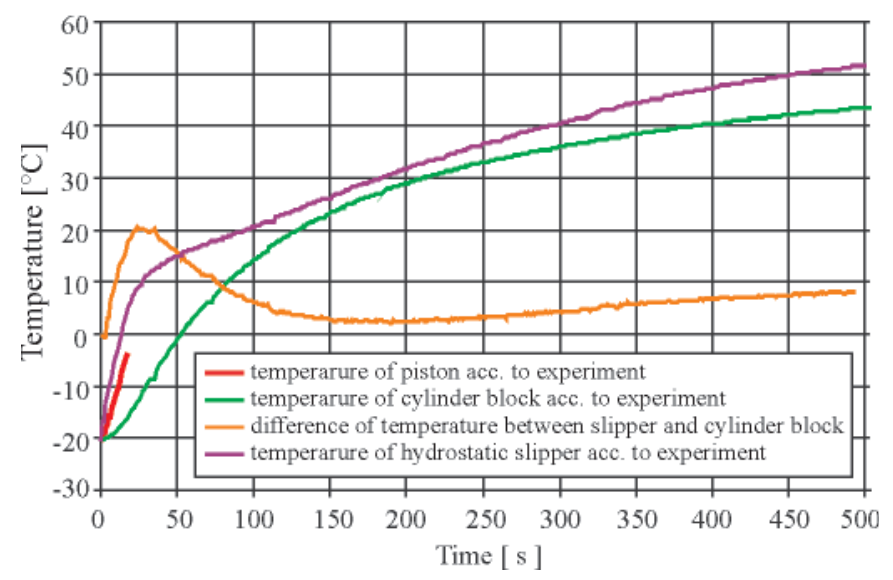

Fig. 13. Changes in temperature of piston hydrostatic slipper and cylinder block and difference of temperatures between piston and cylinder block for start-up parameters: ambient temperature $-20^{\circ} \mathrm{C}$, oil temperature $48^{\circ} \mathrm{C}$, rotation speed $1100 \mathrm{rpm}$, pressure above piston $5.2 \mathrm{MPa}$

Changes of temperature result in changes of radial clearance shown in Fig. 14 for pump cooled to $-20^{\circ} \mathrm{C}$ supplied with hot oil $+48^{\circ} \mathrm{C}$ at shaft rotation speed $1100 \mathrm{rpm}$.

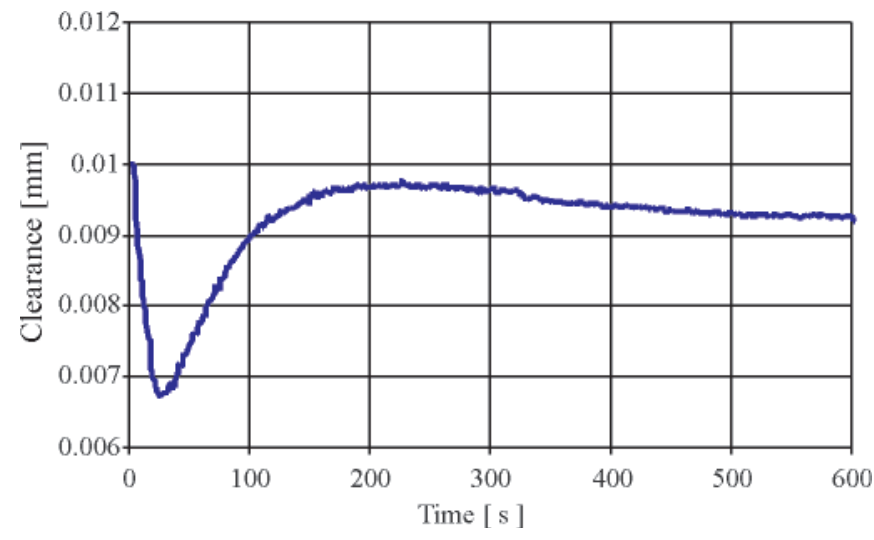

Fig. 14. Change of clearance between the piston and distribution bush for the parameters of pump's operation after start-up: ambient temperature $-20^{\circ} \mathrm{C}$, oil temperature $48^{\circ} \mathrm{C}$, rotation speed $1100 \mathrm{rpm}$, pushing pressure $5.2 \mathrm{MPa}$

The most significant reduction of clearance occurred after ca. 30 seconds after pump's start-up (Fig. 14). It is this period when the biggest difference in temperatures occur between the temperature of the piston and distribution bush. Further on, during start-up the temperatures of cooperating elements become even resulting in increase of radial clearance to desired value.

\section{RESEARCH OF THE GEAR PUMP PZ2-K10 OPERATING AS MOTOR}

In the pump or gear motor the reduction of radial clearance between teeth points and internal surface of the housing may occur.
The lack of axial clearance however will not occur because the pump includes mobile elements providing compensation for axial clearances. Also the jamming of bearing's casing made of steel in the housing made of aluminium will not occur. Based on geometric measurements it was determined that the radial assembly clearance in the tested pump PZ2-K10 (Fig. 15) amounts to $0.087 \mathrm{~mm}$ in the ambient temperature of $20^{\circ} \mathrm{C}$.

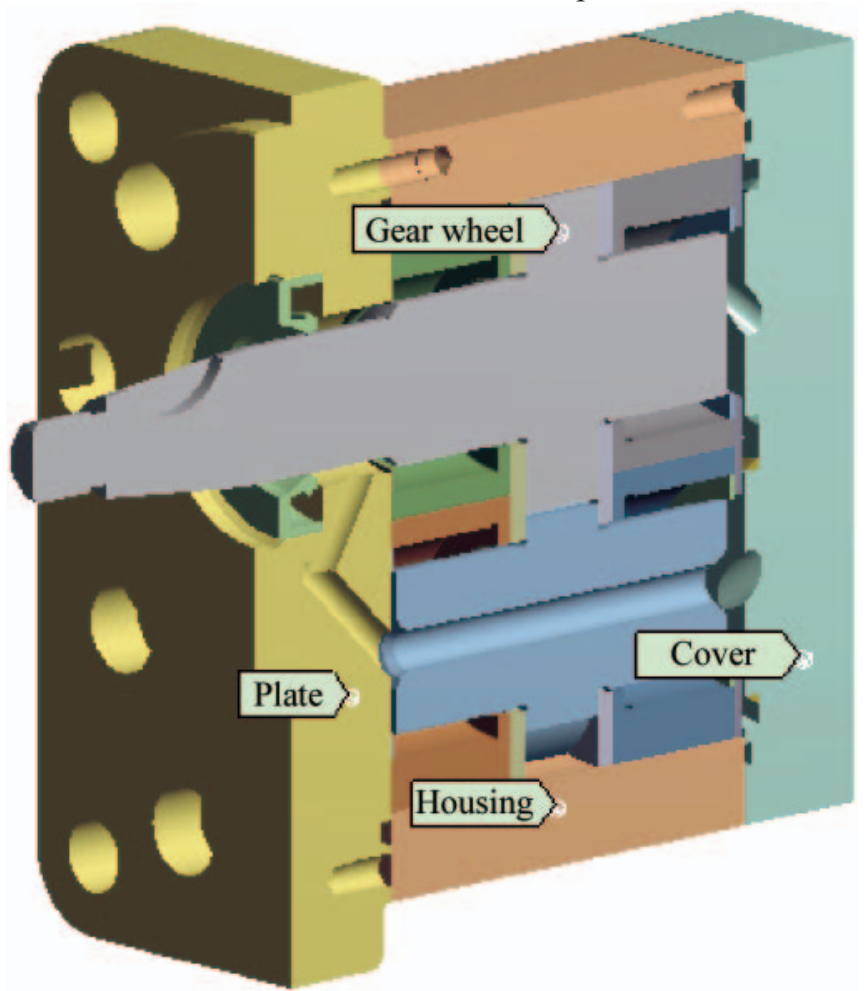

Fig. 15. Places of temperature measurement in gear pump PZ2-K10 elements: plate, cover, gear wheel, housing

According to the equation 1 the effective clearance not only depends on assembly clearance but also on deformation of elements due to influence of pressure and different thermal expansion on cooperating elements. The higher the oil pressure, the bigger is the slack of gear shaft and its displacement inside the bearing. This in turn affects the dimensions of gaps between cooperating elements. It has been assessed that at the maximum operating pressure of the tested pump the displacement of gear shaft in the bearing and its slack may reach $21 \mu \mathrm{m}[17,19]$. This would cause the decrease in dimension of gap between gear teeth tips and hole in the housing on the suction space side.

The change in element's dimensions due to difference in thermal expansion of gear pump elements with housing made of aluminium alloy in thermal shock conditions is described by the following equation:

$$
\begin{aligned}
& \Delta \mathrm{l}_{\mathrm{t}}(\tau)=11 \cdot 10^{-6} \cdot \mathrm{h}_{\mathrm{Z}} \cdot\left[\mathrm{T}_{\mathrm{Z}}(\tau)-293\right]+ \\
& -22.3 \cdot 10^{-6} \cdot \mathrm{h}_{\mathrm{K}} \cdot\left[\mathrm{T}_{\mathrm{K}}(\tau)-293\right][\mathrm{m}]
\end{aligned}
$$

where:

$\mathrm{h}_{\mathrm{Z}}, \mathrm{h}_{\mathrm{K}} \quad-$ linear dimensions: tip diameter of gear tooth $(\mathrm{Z})$ and housing opening diameter $(\mathrm{K})[\mathrm{m}]$

$\mathrm{T}_{\mathrm{Z}}(\tau), \mathrm{T}_{\mathrm{K}}(\tau)$ - temperature of gear wheel and housing in the process of heating up [K]

- temperature of linear measurement of components [K].

Since the linear thermal expansion coefficient for aluminium alloy is almost twice that of steel when lowering the ambient temperature the initial clearance will also decrease. (Fig. 16). 


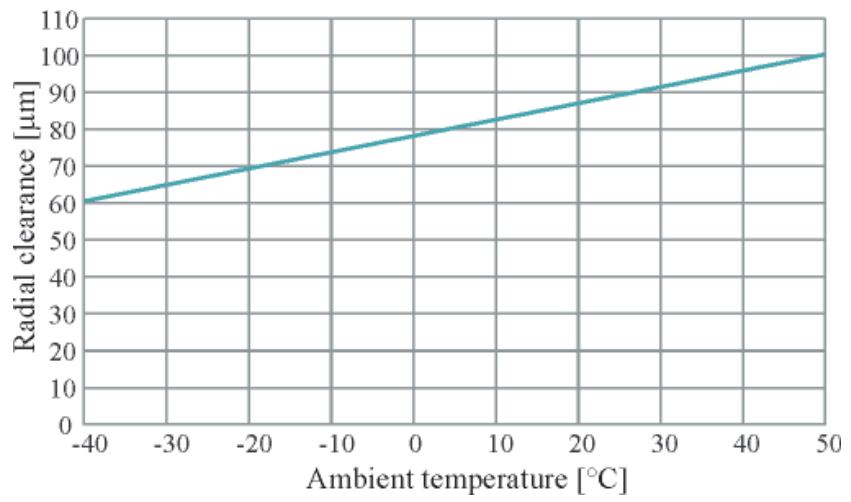

Fig. 16. Initial radial clearance in PZ2-K10 gear pump (motor) depending on ambient temperature

Based on experimental research, the courses of temperature changes in housing and gear wheel of PZ2-K10 pump (operating as motor) were determined for the flow volume in the range of: from $4.5 \mathrm{dm}^{3} / \mathrm{min}$ to $14 \mathrm{dm}^{3} / \mathrm{min}$ and motor's load: from $0.5 \mathrm{Nm}$ to $17 \mathrm{Nm}$.

One of the tests was conducted for the following parameters: oil temperature $48^{\circ} \mathrm{C}$, ambient temperature $-16.8^{\circ} \mathrm{C}$, working pressure $5 \mathrm{MPa}$, pumps rotation speed $1020 \mathrm{rpm}$.

It is to be noticed, that the gear wheel heated up quicker than the housing. Maximum difference in temperatures between heating elements of the unit reached $12^{\circ} \mathrm{C}$ in the 80th second after pump's start-up (Fig. 17).

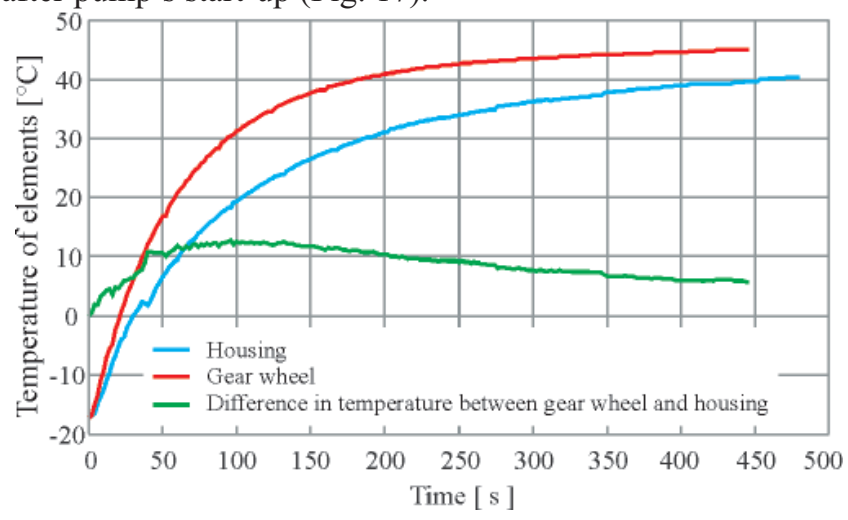

Fig. 17. Temperature of housing, gear wheel and difference in temperatures between those elements of PZ2-K10 pump operating as motor.

Based on temperature changes graph acc. to Fig. 17 it is clear that during gear pump start-up the rapid decrease of radial clearance between teeth tips and internal surface of housing does not occur (Fig. 18). In case of hydraulic components made of aluminium alloys (housing) and steel (wheel) the disappearance of radial clearance doesn't occur.

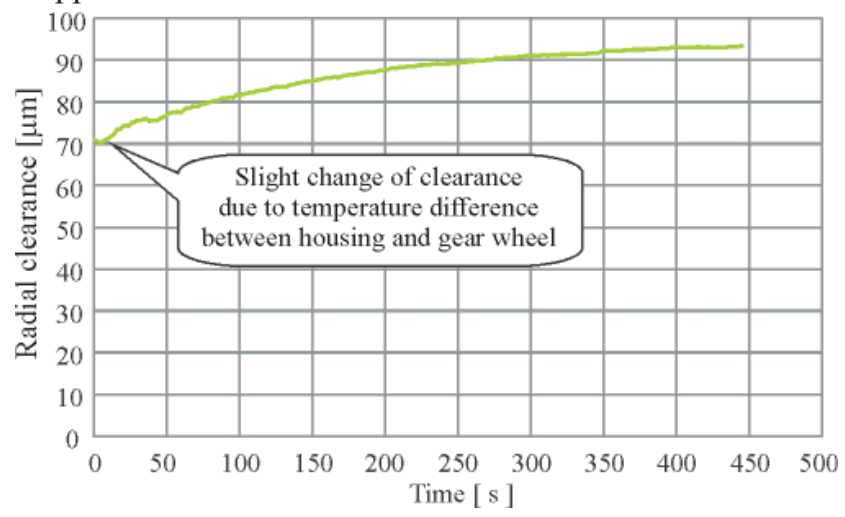

Fig. 18. Change of effective clearance between tips of teeth and internal housing of PZ2-K10 pump operating as motor, during start-up under following conditions: oil temperature $48^{\circ} \mathrm{C}$, ambient temperature $-16.8^{\circ} \mathrm{C}$, working pressure $5 \mathrm{MPa}$
In case of pumps and gear motors with housings made of cast iron the changes of clearance will look differently than on Fig. 18. Such components will be susceptible to thermal shock conditions.

\section{RESEARCH OF INADEQUATE OPERATION OF DIRECTIONAL SPOOL VALVES IN THERMAL SHOCK CONDITIONS}

When in a hydraulic circuit a sudden case of hot oil flowing through cold valve (thermal shock conditions) occurs the uneven heating of cooperating elements of spool and casing will follow. The spool is much smaller than the casing, therefore it's thermal capacity is far smaller. In comparison to the casing it has relatively large surface flushed by passing oil. Therefore it will heat up much faster. With rising temperature of the spool its dimension increase faster against the opening in the casing leading to the decrease of the clearance. The clearances are already quite small in order to minimize leakages. Too small clearances between the spool and casing may result in substantial friction forces hindering or even preventing their movement against each other. Depending on the construction of the component and its maker the clearances between the spool and casing fit in the range of $5-25 \mu \mathrm{m}$ [18].

Effective clearance $\left(1_{\mathrm{e}}\right)$ between casing and spool (Fig. 19, 20) depends on assembly clearance $\left(1_{\mathrm{m}}\right)$, elastic distortions of spool valve's elements due to pressure $\left(\Delta \mathrm{l}_{\mathrm{p}}\right)$, difference in thermal expansion of various components $\left(\Delta \mathrm{l}_{\mathrm{t}}^{\mathrm{p}}\right)$.

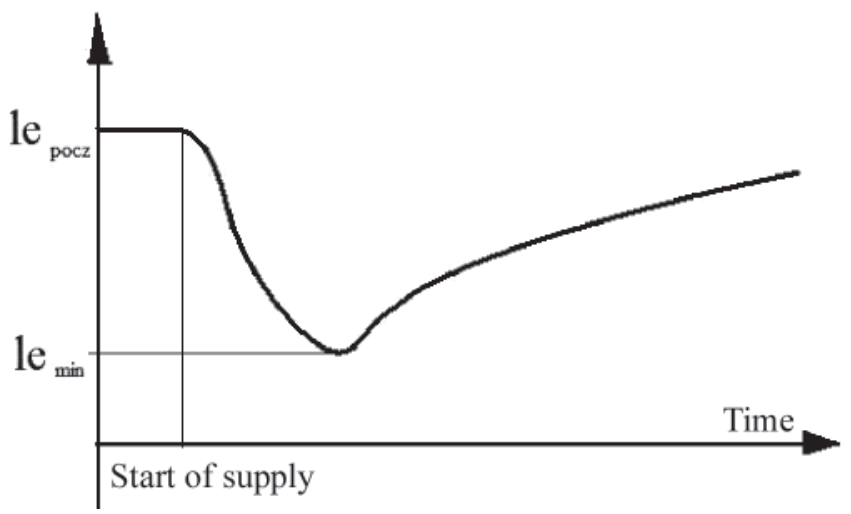

Fig. 19. Change of effective clearance between spool and casing of cooled spool valve fed with hot oil during start-up

In thermal shock conditions the operation of the spool valve is seriously affected by the thermal expansion characteristic of materials used for making specific elements of the spool valve. Spools of hydraulic spool valves are made of steel while their casings are usually of cast iron. The linear expansion coefficient for cast iron equals $10.5^{*} 10^{-6} 1 / \mathrm{K}$, while for steel it is $11 * 10^{-6} 1 / \mathrm{K}[14,15]$.

Taking under account the influence of thermal expansion coefficients the effective clearance may be calculated from the relation of (1) and (2).

Based on numerical calculations it was assessed that the influence of pressure on effective clearance is of lesser importance that the influence of substantial disproportion in temperature of cooperating elements (spool and casing). The confirmation of the fact is found through the calculations of the difference in thermal expansion $\Delta \mathrm{l}_{\mathrm{t}}$ and distortions resulting from the influence of pressure $\Delta \mathrm{l}$ performed for the spool valve RE2510/101 from Hydrotor (Fig. 21), where the spool diameter measured $18 \mathrm{~mm}$. With the spool and casing temperature at $\Delta \mathrm{T}=20^{\circ} \mathrm{C}$ the assembly clearance will decrease by $\Delta \mathrm{l}_{\mathrm{t}}=3.9 \mu \mathrm{m}$, 
for the temperature difference $\Delta \mathrm{T}=45^{\circ} \mathrm{C}$ it will decrease by $\Delta \mathrm{l}_{\mathrm{t}}=8.7 \mu \mathrm{m}$. The influence of oil pressure $(16 \mathrm{MPa})$ on components of the spool valve will only cause the assembly clearance to change by $\Delta \mathrm{l}_{\mathrm{p}}=1.5 \mu \mathrm{m}$.

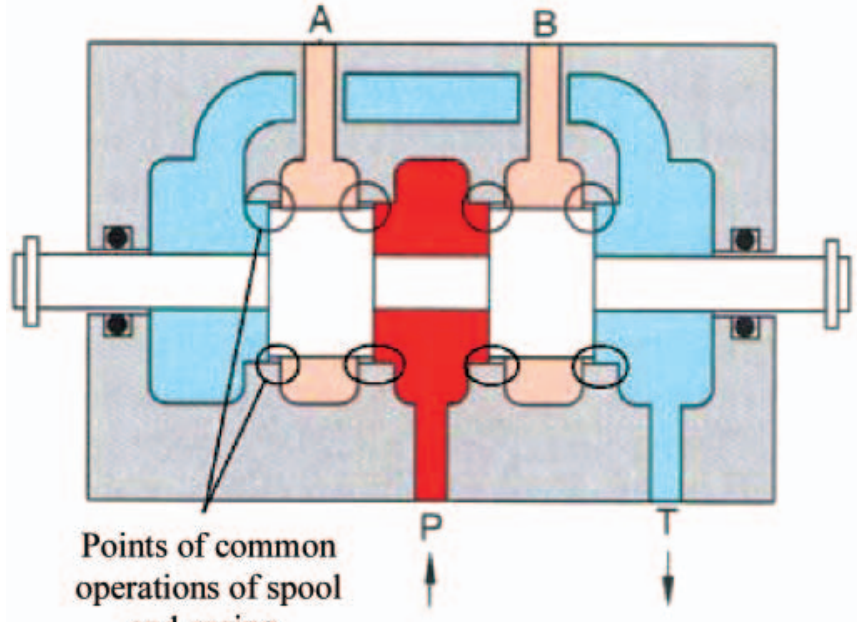

and casing

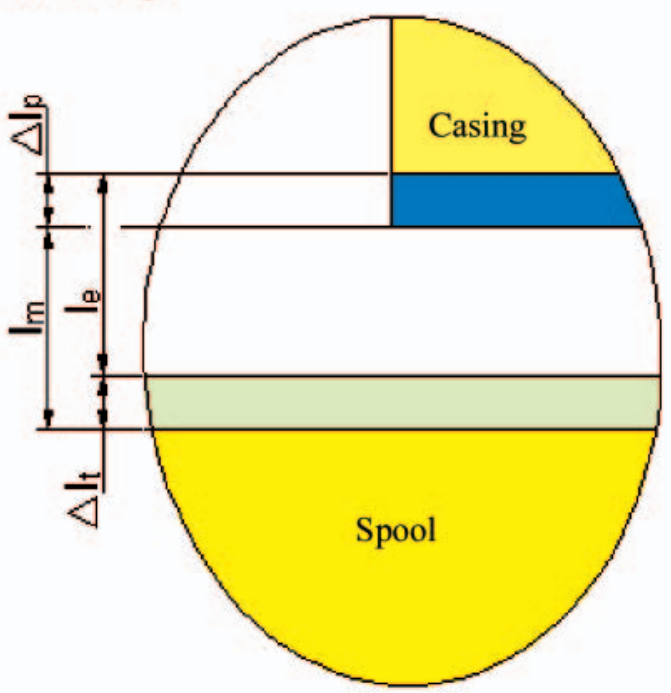

Fig. 20. Points of common operation of spool and casing and graphical interpretation of change of effective clearance

\section{SPOOL VALVES TESTED IN LOW AMBIENT TEMPERATURES}

In the lab of the Chair of Hydraulics and Pneumatics Gdańsk University of Technology following valves for control the pressure and flow direction were tested in thermal shock conditions $[5,6]$ :

+ relief valve type UZPP16 from PONAR WADOWICE company

+ relief valve type DBW 20 A2-5X/350YS6EG24N9K4R12 from REXROTH company

+ dual stage spool valve 4WEH16C33/6AW220-50 from REXROTH company

+ electro hydraulically controlled spool valve RE2510/101 from HYDROTOR company (Fig. 21)

+ proportional spool valve PVG 32 from SAUER DANFOSS company (Fig. 22)

+ servovalve 4WS2EM10 - 45/20B2T315Z8EM from REXROTH company (Fig. 23).

Hydraulic units are often fitted with electro-hydraulically controlled spool valve. Therefore many constructions of electrically controlled hydraulic valves were tested.

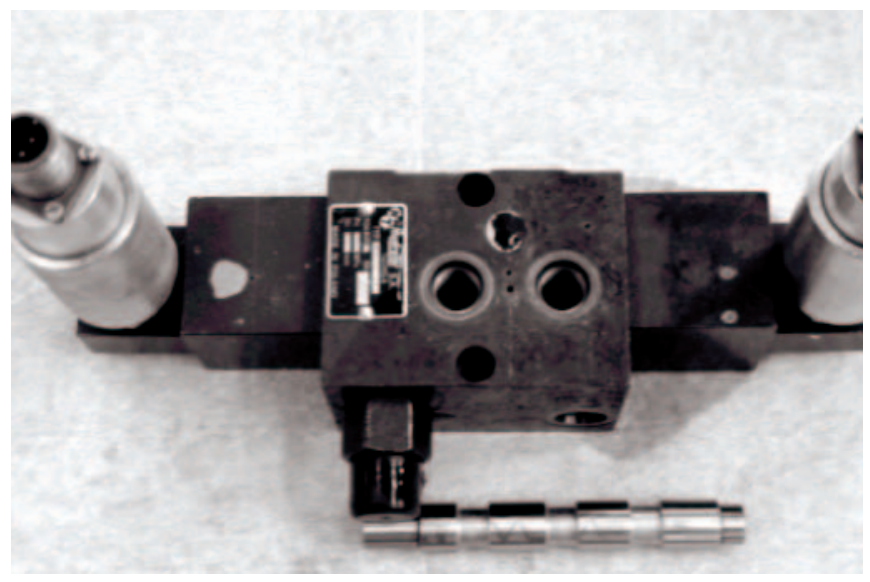

Fig. 21. Electro-hydraulic spool valve RE2510/101 [19]

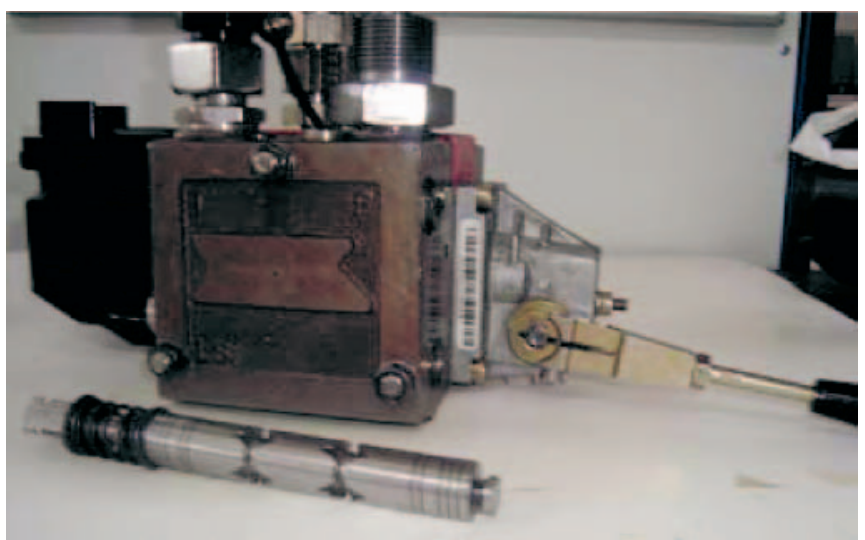

Fig. 22. Proportional spool valve PVG 32 [22]

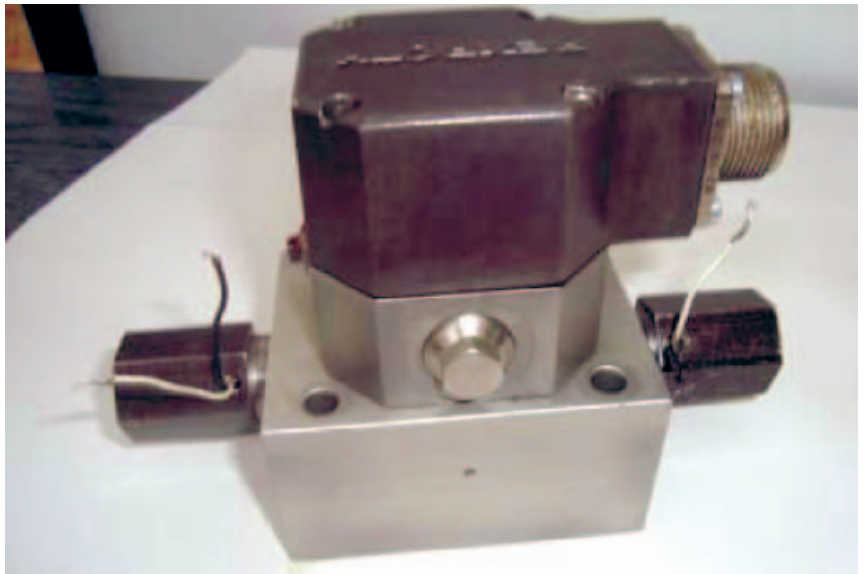

Fig. 23. Servovalve 4WS2EM10 - 45/20B2T315Z8EM [18]

Tested sliding spool valve belong to two groups depending on their function:

I - spool valve used for controlling the flow direction classical (Fig. 21, 24)

II - proportional spool valve and servovalves additionally used to control the volume of flow (Fig. 22, 23, 25, 26).

Nominal diameters of spools in case of PVG 32 and RE2510/101 spool valve amounted to $18 \mathrm{~mm}$. Initial clearance between spool and casing in PVG 32 spool valve amounted $7 \mu \mathrm{m}$, while in RE2510/101 spool valve it was $6 \mu \mathrm{m}$ (measurements performed at Metrology Lab of Gdańsk University of Technology).

In the body of RE2510/101 spool valve (Fig. 24) bores were made for placing thermocouples. Bores for thermocouples T7 and T8 are placed in axis but on different depths, near the source of flowing oil while the bore for thermocouple T3 is 
away from the hot oil channel. In order to test the spool two bores were made to accommodate thermocouples. The bores were made in axis however to different depths. One of the bores was located near the place where cylindrical surface of the spool was flushed with hot oil. The other was located at the spool 's front.
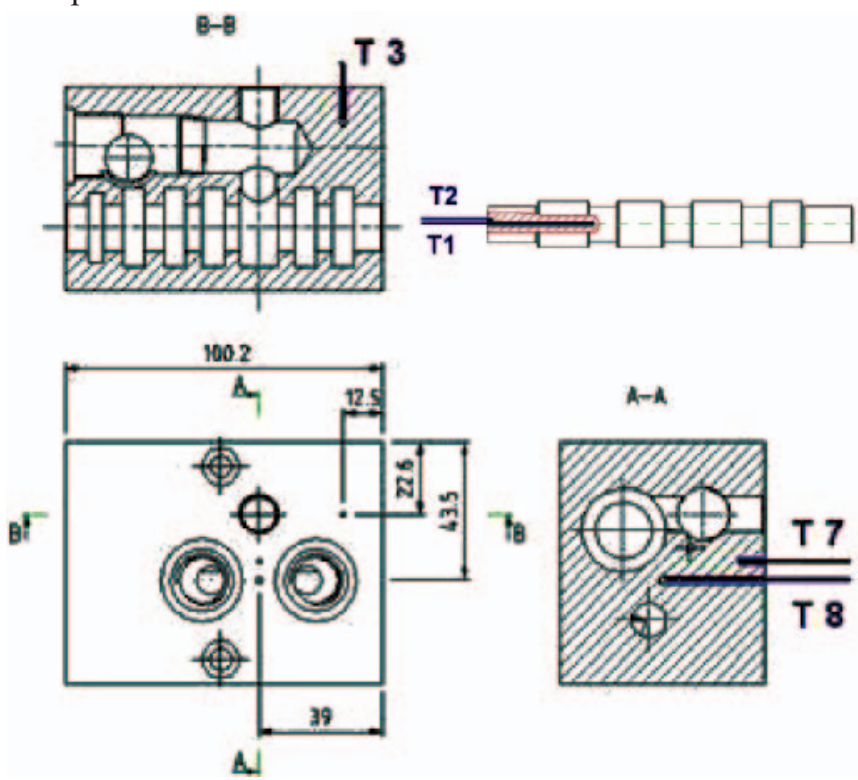

Fig. 24. Spool valve RE2510/101 from Hydrotor company T1, T2 thermocouples placed in spool T3, T7, T8 - thermocouples placed in casing
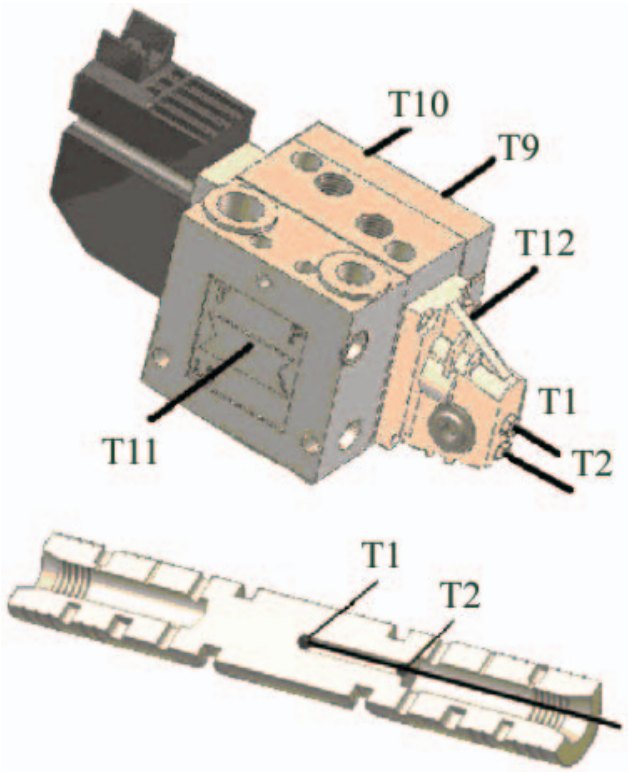

Fig. 25. Spool valve PVG 32 from Sauer Danfoss. T1, T2- thermocouples located in the spool T9, T10, T11, T12 thermocouples located in the fixed elements of the spool valve

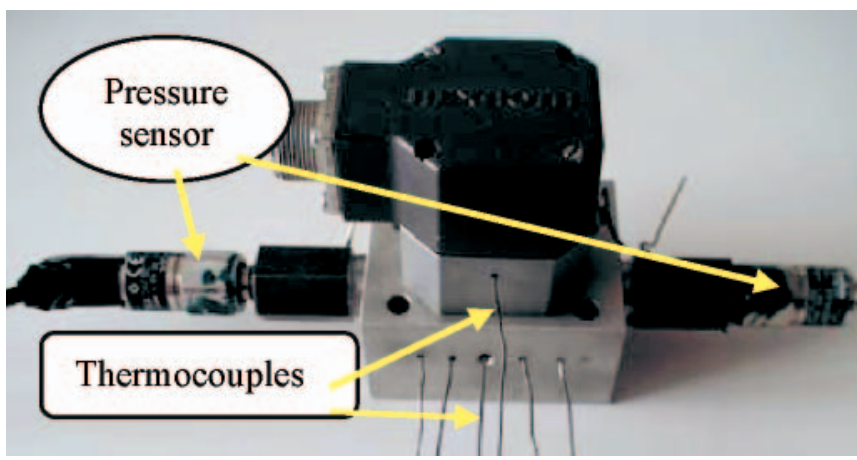

Fig. 26. Servovalve 4 WS2EM10 - 45/20 from Rexroth with temperature (thermocouples) and pressure sensors
For the purpose of measuring the heating up of PVG 32 spool valve the bores were made in spool and casing in which thermocouples were inserted. Their layout is presented on Fig. 25 . In the spool a bore was made reaching half of its length. T1 thermocouple was inserted into the full depth of the bore while the T2 was placed in its beginning. T9, T10, T11 and T12 thermocouples were placed in fixed elements of the spool valve.

The diameter of the researched servovalve 4WS2EM10 is $6,495 \mathrm{~mm}$, while the clearance between the spool and cylindrical bush in the casing is $5 \mu \mathrm{m}$.

In the fixed elements of 4WS2EM10 - 45/20 servovalve 11 thermocouples were placed (Fig. 26), allowing for presentation of heating processes for various states of supply. Through pressure indication, the pressure sensors (Fig. 26) enabled the determination of reaction time to the control signal and change of this time with changing ambient temperature.

\section{SAMPLE RESULTS OF TESTING PVG 32 SPOOL VALVE}

Several tests series of PVG 32 spool valve were conducted for the temperature differences between hot oil and cooled unit kept in the range of $\Delta \mathrm{T}=20 \div 75 \mathrm{~K}$.

One test of the spool valve cooled to $0^{\circ} \mathrm{C}$ was conducted at abrupt changes of flowing oil pressure from zero to $32 \mathrm{dm}^{3} / \mathrm{min}$ at temperature $52^{\circ} \mathrm{C}$. The difference in temperature between the spool and casing was determined (Fig. 27). Maximum difference in temperature between the body and the spool during heating reaches $27.9^{\circ} \mathrm{C}$ and occurs in the 30th second. In this time the temperature of casing is $13.8^{\circ} \mathrm{C}$ and spool 's $41.7^{\circ} \mathrm{C}$.

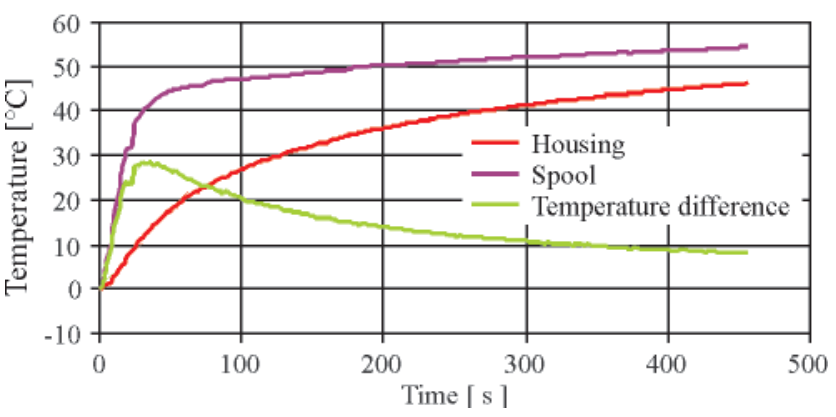

Fig. 27. Average temperatures of casing and spool and the difference in temperatures between the two during feeding: oil temperature $52^{\circ} \mathrm{C}$, ambient temperature $0^{\circ} \mathrm{C}$, flow volume $32 \mathrm{dm}^{3} / \mathrm{min}$

Using the formula (1) under assumption that the distortion of the spool and the casing due to pressure are negligible, the effective clearance between the components was determined (Fig. 28).

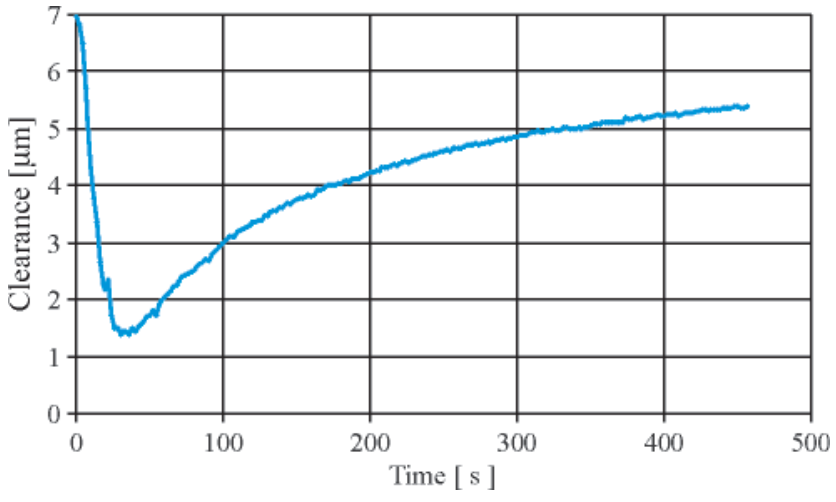

Fig. 28. Effective clearance between external surface of the spool and internal surface of the casing during feeding: oil temperature $52^{\circ} \mathrm{C}$, ambient temperature $0^{\circ} \mathrm{C}$, flow volume $32 \mathrm{dm}^{3} / \mathrm{min}$ 
Based on the effective clearance graph (Fig. 28) it is possible to determine that the disappearance of clearance between spool and casing due to difference in thermal expansion between the two will not occur.

\section{RESEARCH OF THE LOW SPEED HYDRAULIC MOTORS}

The first part of the article [8] deals with symptoms of correct and incorrect operation of hydraulic motors in thermal shock conditions based on pressure and turning speed. The results of tests of satellite hydraulic motor were presented.

Also low speed orbital hydraulic motors without axial clearance compensation were tested in low ambient temperatures. Such motors are commonly used in driving arrangements of machines.

Researched satellite motor SOK 100 from ZUO Hydroster [20] (Fig. 30) of geometric working capacity $0.4 \mathrm{dm}^{3} / \mathrm{rev}$. may operate at the range of speed from 0 to $160 \mathrm{rpm}\left(\mathrm{n}_{\max }=250 \mathrm{rpm}\right)$ and nominal pressure $\mathrm{p}_{\mathrm{n}}=16 \mathrm{MPa}\left(\mathrm{p}_{\max }=25[\mathrm{MPa}]\right)$. Assembly axial clearance was $23 \mu \mathrm{m}$.

Orbital motor GMR 160 from Rexroth (Fig. 33) [18] of geometric working capacity $162.9 \mathrm{~cm}^{3} / \mathrm{rev}$ according to its maker is characterized by nominal speed of $375 \mathrm{rpm}\left(\mathrm{n}_{\max }=\right.$ $=470 \mathrm{rpm}$ ), nominal pressure $\mathrm{p}_{\mathrm{n}}=12 \mathrm{MPa}$ and max. pressure $\mathrm{p}_{\max }=22.5 \mathrm{MPa}$.

TF170MW260 motor from Parker company[21] of geometric working capacity $169 \mathrm{~cm}^{3} / \mathrm{rev}$ according to its maker may be operated continuously up to the nominal speed of $355 \mathrm{rpm}$ and nominal difference in pressure (between in and outtake) $13.8 \mathrm{MPa}$, and momentarily at $\mathrm{n}_{\max }=440 \mathrm{rpm}$ and $\max$. pressure difference $20.7 \mathrm{MPa}$. The maximum supply pressure may reach $30 \mathrm{MPa}$.

\section{PREPARATION AND SAMPLE RESULTS OF TESTING THE SOK 100 MOTOR (FIG. 29) CONDUCTED IN THERMAL SHOCK CONDITIONS}

The motor was made to specific order at ZUO HYDROSTER in Gdańsk. In the fixed elements specials bores for thermoelectric sensors were made for measuring temperature in front and rear covers and the housing. Following that, the motor was assembled with semiconductor temperature sensors (AD590) placed in mobile elements (two sensors in the rotor and one in the shaft).

$$
\text { A-A }
$$
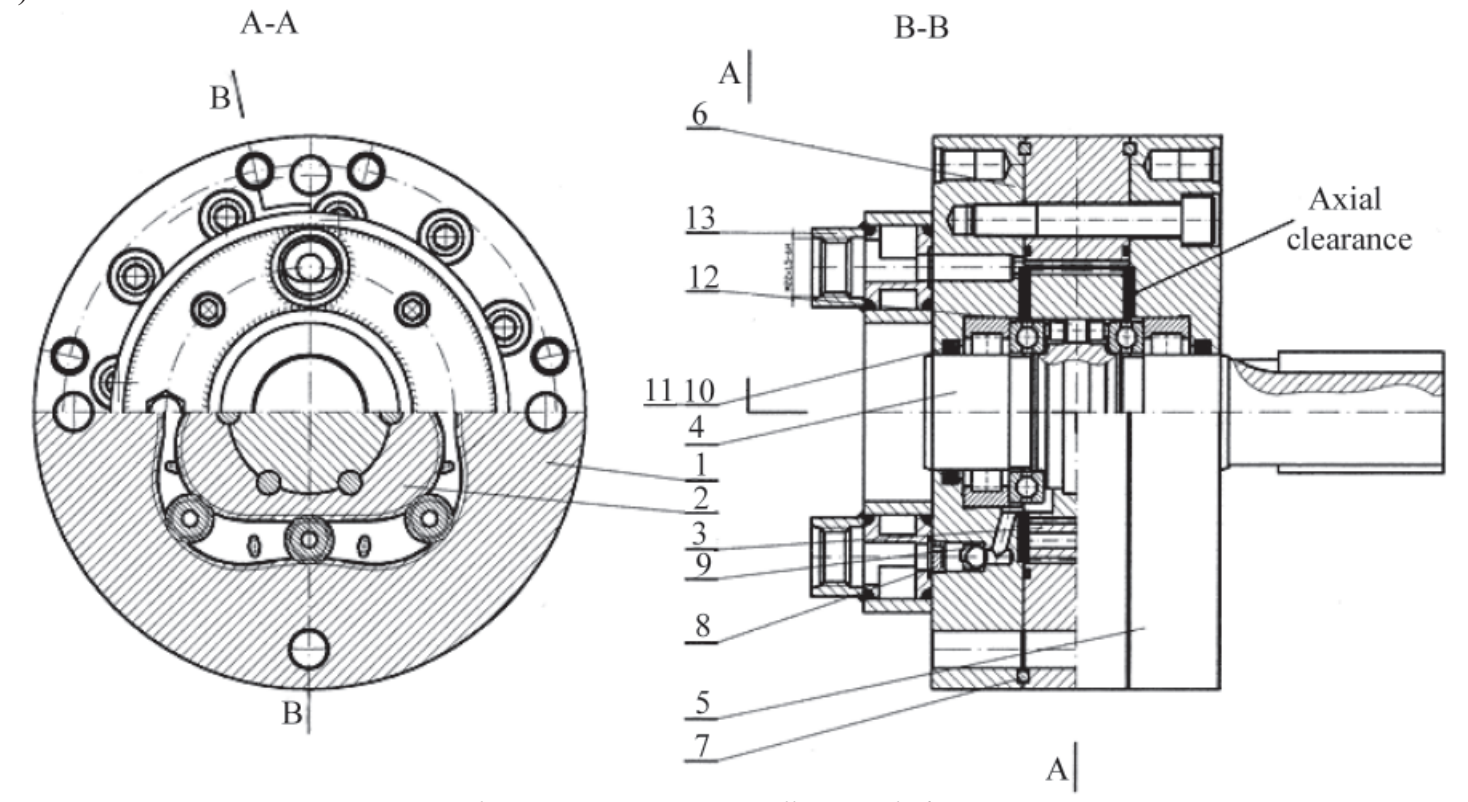

One test of SOK 100 when the motor operated incorrectly was conducted for the following conditions: flow volume $100 \mathrm{dm}^{3} / \mathrm{min}$, initial temperature $-20^{\circ} \mathrm{C}$, oil temperature $50^{\circ} \mathrm{C}$.

Start-up of motor in this conditions caused substantial rise of temperature in mobile elements of the motor. The satellites heated quicker than the rotor. Fig. 30 presents the graphs of temperature in rotor and housing. The substantial rise in rotor's temperature is clearly visible (Fig. 30). This, in turn results in great difference in temperatures of the rotor and housing leading to disappearance of clearance between the two (Fig. 31). Substantial rise in temperature caused the dry friction between the elements.

In result the friction heat appeared directly effecting elements of the motor. In turn satellites and rotor heated up quicker.

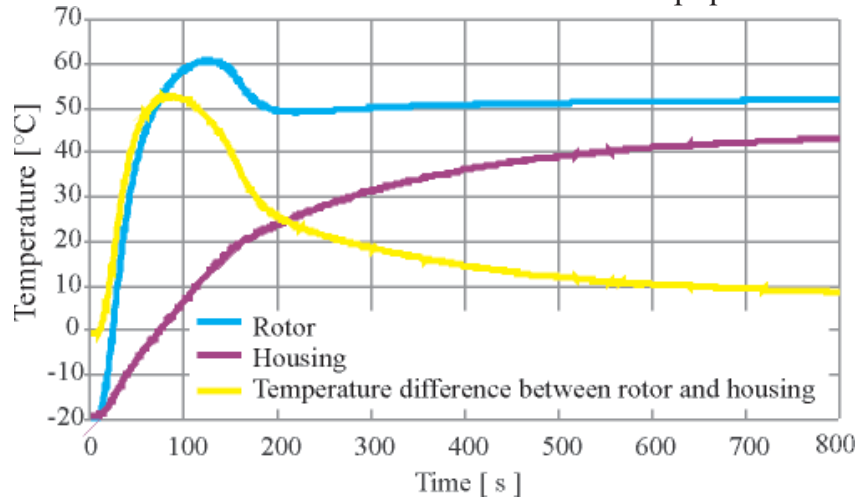

Fig. 30. Temperature of rotor and housing with difference in temperatures

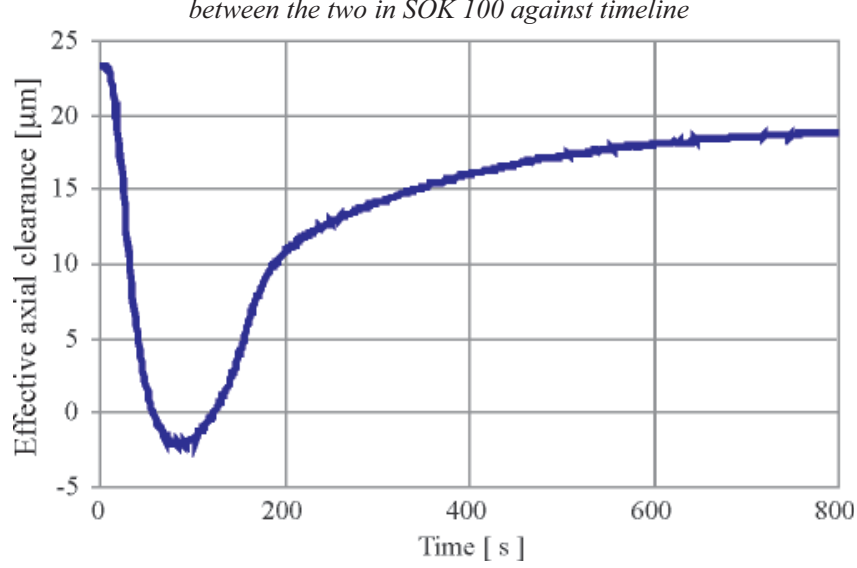

Fig. 31. Change of effective clearance between the covers and rotor of SOK 100 during start-up in thermal shock conditions

Fig. 29. Motor SOK: 1 -housing; 2 -rotor; 3 -satellite; 4 -shaft; 5, 6 -covers; 7 -setting ring; 8,9 - non-return valve; 10,11 - rings; 12 - pin; 13 - manifold 

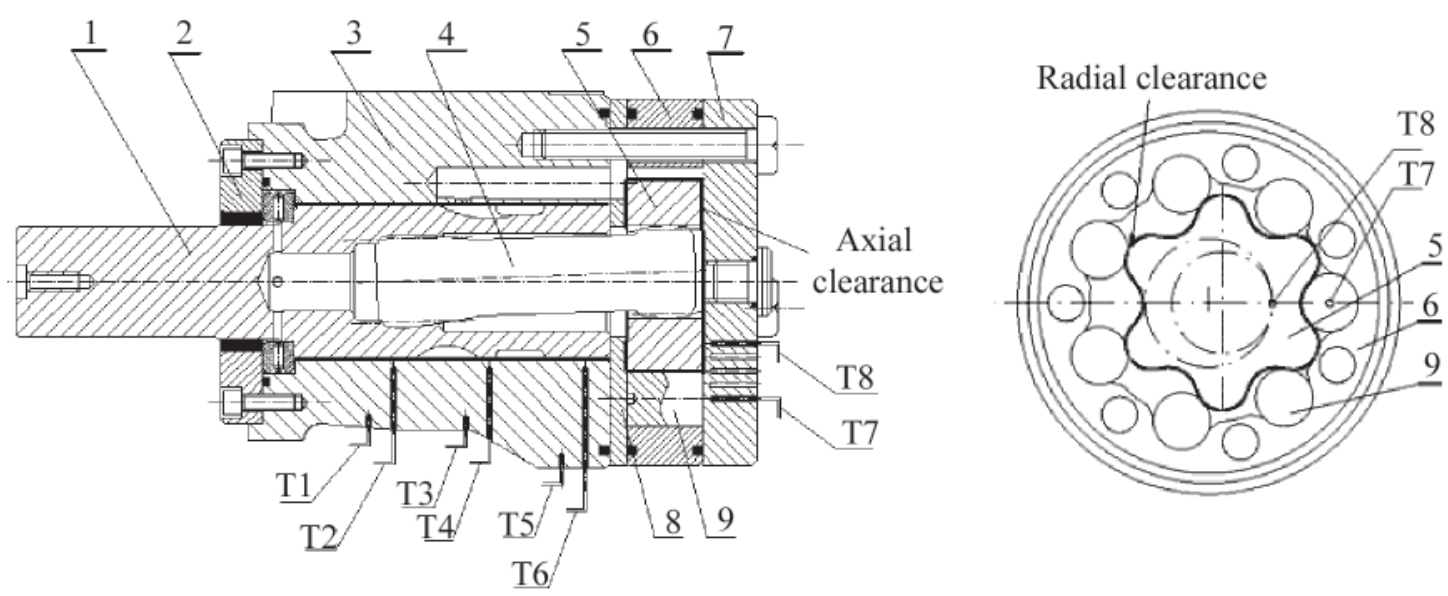

Fig. 32. Orbital motor GMR 160 with temperature sensors: $\mathbf{1}$-shafting, $\mathbf{2}$-front cover, $\mathbf{3}$ - housing, $\mathbf{4}$ - geared shaft, $\mathbf{5}$-rotor, $\mathbf{6}$ - body, 7 -rear cover, $\boldsymbol{8}$-distribution disc, $\mathbf{9}$-roller (markings $\boldsymbol{T} \mathbf{1} \div \mathbf{T} \boldsymbol{8}$ indicate place of temperature measuring using thermocouples of the same marks)

\section{PREPARATION OF ORBITAL MOTORS FOR TESTING IN THERMAL SHOCK CONDITIONS}

The orbital GMR 160 motor (Fig. 32) includes construction nodes susceptible to disappearance of clearance in thermal shock conditions.

The nodes are as follows:

- axial gaps between surfaces of rotor, cover and distribution disc

- gaps between perimeter surfaces of rotor's and housing's gear

- gaps between external surface of camshaft and internal surface of housing.

In order to assess specific elements of GMR 160 motor in various places 8 temperature sensors (thermocouples) were placed. In the rear cover thermocouples $\mathrm{T} 7$ and $\mathrm{T} 8$ were placed. Six thermocouples were inserted into the bores in the housing - thermocouples T1, T3, T5 (away from the heat source) and T2, T4, T6 (close to the heat source).

The second orbital motor tested in thermal shock conditions was TF170 (Fig. 33) with frontal distribution.

The motor was prepared for tests by making bores in fixed elements for thermocouples, i.e. in spool valve, housing near the working chamber, housing near the roller, body near the oil channel, body away from the heat source. Sensors were not placed in mobile elements due to complicated kinematics of their operation.

Orbital motors GMR 160 are TF 170 are differentiated by the distribution and the flow of oil through the channels resulting, in turn, in different way of heating up motor's elements.

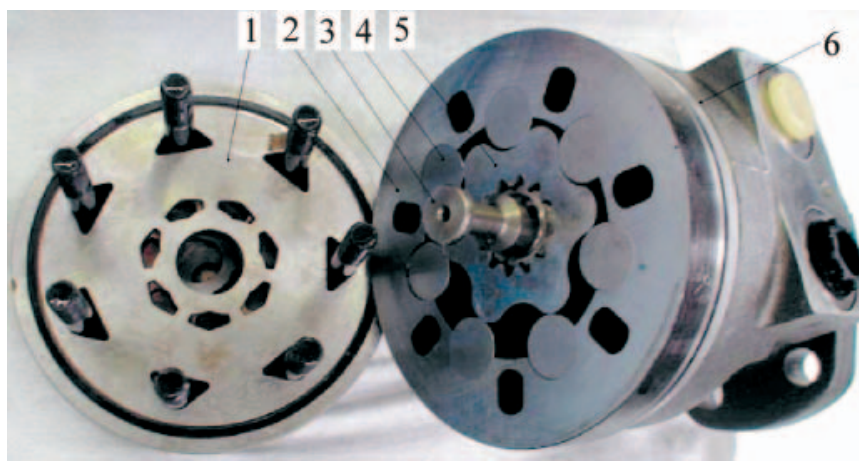

Fig. 33. Orbital motor TF 170: 1 -spool valve, 2 - housing, $\mathbf{3}$ - geared shaft, 4 -roller, $\mathbf{5}$-rotor, $\mathbf{6}$ - body

\section{INFLUENCE OF ORBITAL MOTORS' CONSTRUCTION ON THEIR OPERATION IN THERMAL SHOCK CONDITIONS}

In order to assure proper operation of hydraulic system in thermal shock conditions suitable hydraulic motors, resistant to such conditions have to be used. Such requirements are well met by the tested orbital motor TF 170 from Parker company (Fig. 33, 34). In its housing there are additional channels for flowing oil thus enhancing the surface of heat exchange resulting in quicker heating up of the housing. It was also found out that with such construction (Fig. 35) the maximum difference in temperatures between the housing and rotor didn't exceed $20^{\circ} \mathrm{C}$ during start - up under thermal shock conditions for the temperature difference $\Delta \mathrm{T}_{\text {ol-ot }}$ of oil and surrounding reaching $77^{\circ} \mathrm{C}$.

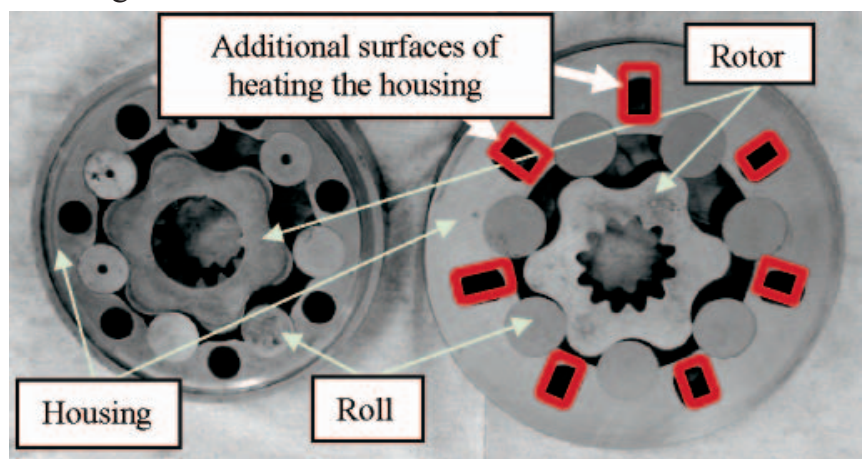

Fig. 34. Components of GMR 160 orbital motor (on the left) and TF 170 (on the right). In the TF 170 motor additional channels for flowing oil are provided

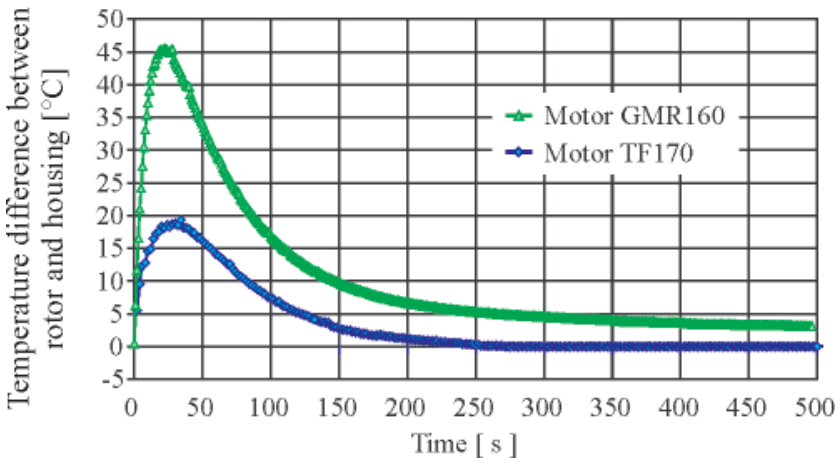

Fig. 35. Difference in temperature between rotor and housing of TF170 motor (volume of flow $64 \mathrm{dm} / \mathrm{min}$, initial temp. of motor $-27^{\circ} \mathrm{C}$, oil temp. $50^{\circ} \mathrm{C}$ ) and $G M R 160$ motor (volume of flow $70 \mathrm{dm}^{3} / \mathrm{min}$, initial temp. $-26^{\circ} \mathrm{C}$, oil temp. $52^{\circ} \mathrm{C}$ 
Orbital motor GMR 160 (Fig. 32 and 34) provides no additional heat exchange surface from oil to housing. It was also found out (Fig. 35) that the maximum difference in temperatures between the rotor and housing reached $46^{\circ} \mathrm{C}$ for $\Delta \mathrm{T}_{\text {ol-ot }} 78^{\circ} \mathrm{C}$.

Having the experimental data as per Fig. 35 and based on the relation (1) change of radial clearance was determined for motors GMR 160 and TF170 (Fig. 36).

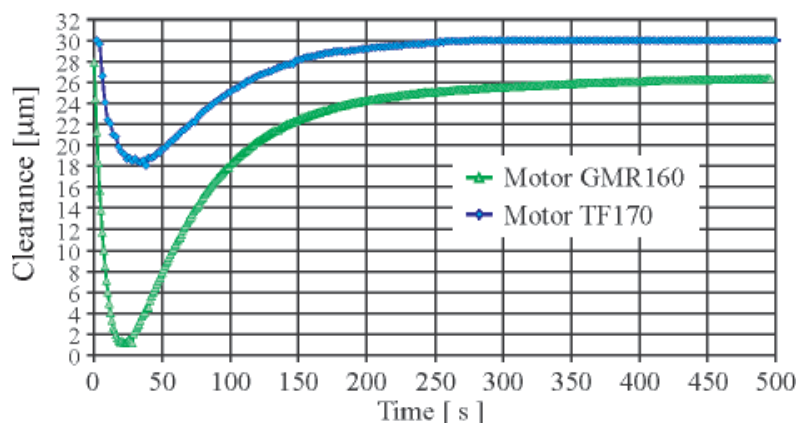

Fig. 36. Graph of radial clearance in TF170 and GMR160 motors (start-up conditions as in case of Fig. 35)

Radial clearance in TF 170 motor, between the rotor and housing decreased maximum by $12 \mu \mathrm{m}$, while in case of GMR160 motor, under similar operating conditions the clearance decreased by $27 \mu \mathrm{m}$ and was close to vanishing completely (Fig. 36).

Thanks to substantial initial clearance the GMR 160 motor proved resistant to thermal shock conditions and operated correctly at temperature difference $\Delta \mathrm{T}_{\mathrm{ol}-\mathrm{ot}}$ of oil and surrounding up to $78^{\circ} \mathrm{C}$.

In case of TF170 motor from Parker during start-up under thermal shock conditions only slight change of radial clearance between the rotor and housing occurs (Fig. 36). This signifies substantial resistance of such motors during operation under given conditions.

\section{SUMMARY}

The main construction issue decisive for admissible supply parameters of cooled hydraulic components in thermal shock conditions is the effective clearance.

Based on temperature graphs acquired from tests of heating up elements of hydraulic components it is possible to determine precisely change of clearance between cooperating elements.

There are many factors influencing change of effective clearance, i.e.: initial clearance, initial temperature of the component, temperature of feeding oil, volume of flow, material used for making the unit and element's construction.

Using suitable materials for cooperating elements of hydraulic components it is possible to protect them fully against thermal shock conditions. This is well exemplified by high speed pumps with housing made of aluminium alloy and gear of steel.

During start-up in thermal shock conditions the supply and executive components present low torque efficiency and therefore low overall efficiency. This is due to substantial friction in working agent flow through the component's channels. One example is the torque efficiency of PWK 27 pump determined for start-up at temperatures $-20^{\circ} \mathrm{C}$ and $+24^{\circ} \mathrm{C}$. During start-up in thermal shock conditions the pump presents decreased torque efficiency (Fig. 37).

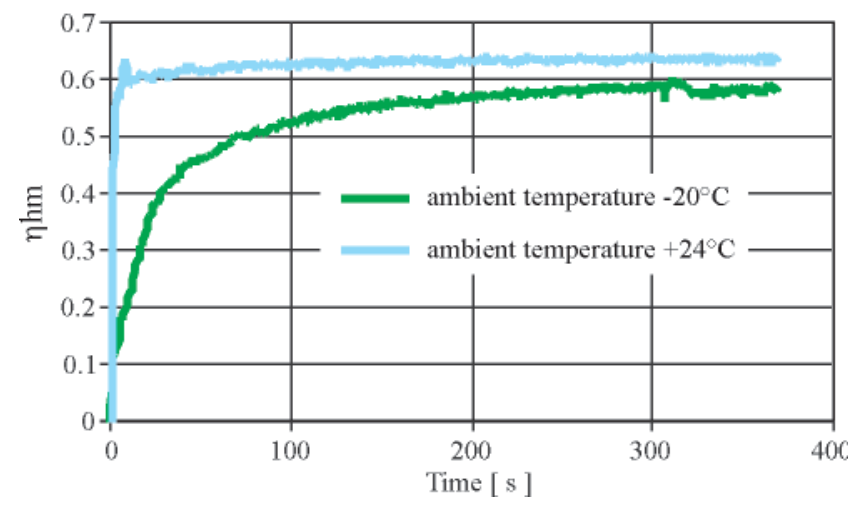

Fig. 37. Hydraulic - mechanical efficiency of start-up of PWK27 pump for the following conditions: ambient temp. $t=+24^{\circ} \mathrm{C}$ and $t=-20^{\circ} \mathrm{C}$, revolution speed $n=1100[\mathrm{rpm}]$, oil temp. $t_{\text {ol }}=48^{\circ} \mathrm{C}$, working pressure $5 \mathrm{MPa}$

O Apart from above described experimental method of determining parameters for correct start-up of hydraulic components in low ambient temperatures, Author uses and recommends two other methods: analytical and computer aided simulation. With the use of these methods one may determine, with suitable precision, parameters for correct start-up of hydraulic system in thermal shock conditions without the necessity of using costly, troublesome and often destructive experimental researches. These methods will be described in following components of this article, concerning issues addressed here.

\section{BIBLIOGRAPHY}

1. Jasiński R.: Operation of low speed hydraulic motors in thermal shock conditions. Doctoral dissertation, thesis supervisor: A. Balawender. Gdańsk 2002.

2. Jasiński R.: Research methodology of low speed hydraulic motors in thermal shock conditions, the IXth Seminar „Drives and control 2003", Gdańsk, February 2003.

3. Jasiński R.: Analysis of permissible start-up parameters for hydraulic motors in thermal shock conditions, the Xth Seminar „Drives and control 2004”, Gdańsk, 2004.

4. Jasiński R.: Operation of hydraulic system control components in low ambient temperatures when supplied with hot working agent, the IIIrd International Technical Diagnostics Congress „Diagnostyka'2004”, Poznań, 2004.

5. Jasiński R.: Operation of hydraulic components in low ambient temperatures. Scientific Conference, Mechanika 2005, Gdańsk 2005.

6. Jasiński R.: Assessment of suitability of hydraulic control components operated in low ambient temperatures, conference papers: Diagnostyka, Olsztyn, 2008

7. Jasiński R.: Experimental research of the multi-piston axial pump PWK 27 from HYDROTOR company in low ambient temperatures, Drives and control, professional journal 4/08

8. Jasiński R.: Problems of the starting and operating of hydraulic components and systems in low ambient temperature (Part I), Polish Maritime Research 4/2008

9. Lewandowski P.: Experimental research of the multi-piston pump PWK 27 during start-up in low ambient temperatures. Graduation paper, thesis supervisor R. Jasinski, Gdańsk 2006.

10.Osiecki A.: Hydrostatic drive of machines. Science-Technical Publishing House, Warszawa 1998.

11.Osiecki L.: Multi-piston pumps with cam distribution. Seminar papers „Drives and control 2003”, Gdańsk 2003.

12.Rutkiewicz Ł.: Experimental research of proportional valve in low ambient temperatures, Graduation paper, Thesis supervisor: R. Jasiński, Gdańsk Polytechnics, 2006. 
13.Szałkowski S.: Research of hydraulic directional spool valve in thermal shock conditions, Graduation paper, Thesis supervisor: R. Jasiński, Gdańsk Polytechnics, 2004.

14.Chełmińska H. and others: Characteristics of steel, volume 1, part 1, „Ślask” Publishing House, Katowice, 1975.

15.Niezgodziński M., Niezgodziński T.: Formulas, graphs and strength charts, PWN Publishing House, Warszawa 1984.

16.Przychodzień T. and others: Operation of machines in winter conditions. Warszawa, WNT Publishing House 1990.

17.Szydelski Z., Olechowicz J.: Parts of hydraulic and pneumatic drive and control. PWN Publishing House, Warszawa 1986.

18. Books and catalogues from Bosch Rexroth company

19. Catalogues from Hydrotor company

20.Catalogues from ZUO Hydroster company

21.Catalogues from Parker company
22.Catalogues from Sauer-Danfoss company

23.Hydrostatic axial piston machine. European patent No. 0742870. Inventor: Osiecki A., Osiecki L. 1999

24.Hydrostatic axial piston machine. Polish patent No. 173937. Inventor: Osiecki A., Osiecki L. 1999

\section{CONTACT WITH THE AUTHOR}

Ryszard Jasiński, Ph. D.

Faculty of Mechanical Engineering Gdansk University of Technology

Narutowicza 11/12

80-952 Gdansk, POLAND

e-mail: rjasinsk@pg.gda.pl

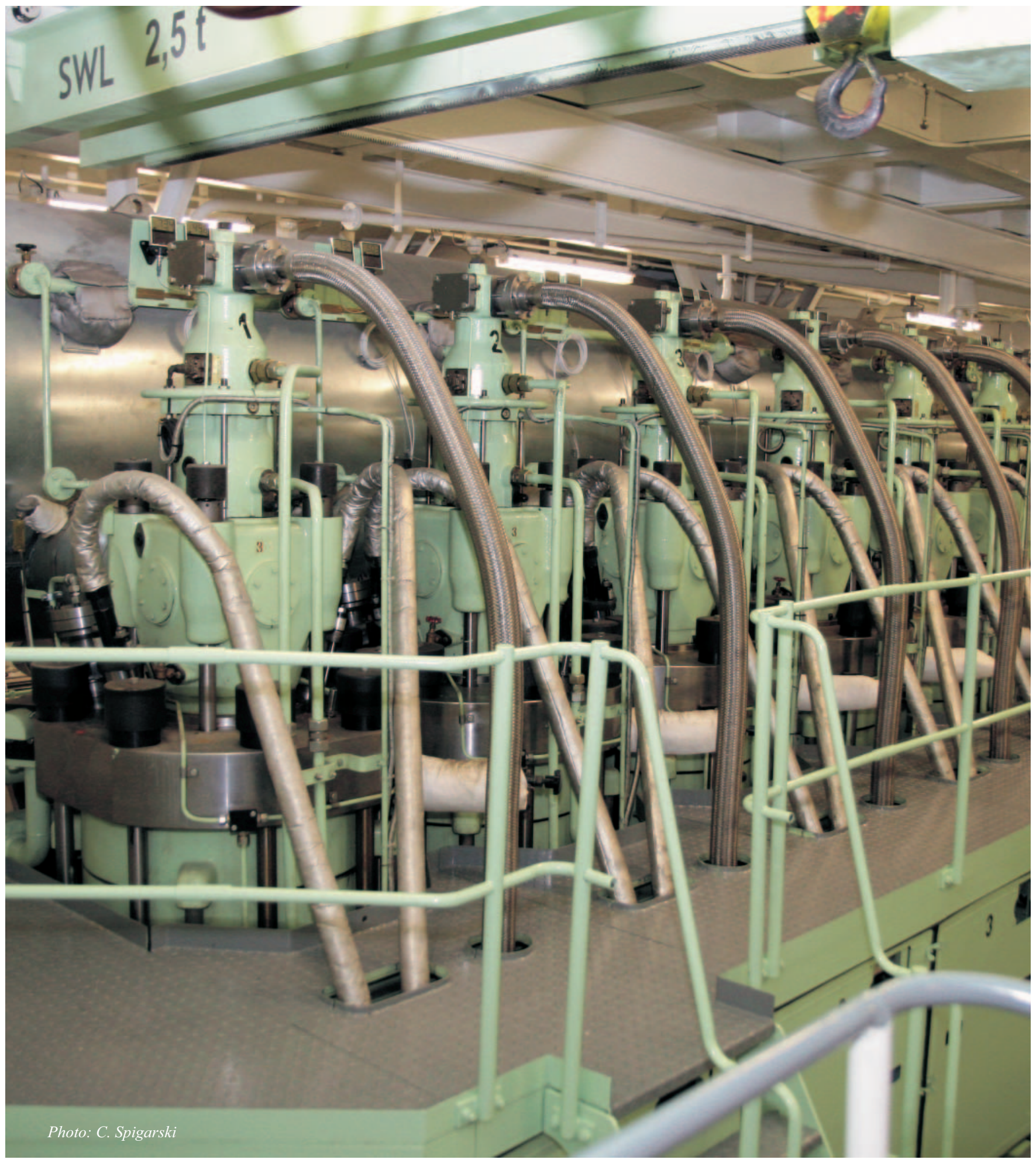

